\title{
Long term Temperature and Precipitation Trends Assessment in the state of Qatar and its Implication to Energy Water and Food Nexus
}

Al-Ansari Tareq ( $\boldsymbol{\nabla}$ talansari@hbku.edu.qa )

Hamad bin Khalifa University

Govindan Rajesh

Hamad bin Khalifa University

Hazrat Bilal

Hamad bin Khalifa University

\section{Research Article}

Keywords: Climate change, EWF nexus, Urbanization, Trends, Variability

Posted Date: January 13th, 2021

DOl: https://doi.org/10.21203/rs.3.rs-140066/v1

License: (1) This work is licensed under a Creative Commons Attribution 4.0 International License.

Read Full License 


\title{
Long term Temperature and Precipitation Trends Assessment in the state of Qatar and its Implication to Energy Water and Food Nexus
}

\author{
Hazrat Bilal ${ }^{1}$, Rajesh Govindan, ${ }^{2}$ Tareq Al-Ansari ${ }^{\mathrm{i}, 2 *}$ \\ ${ }^{I}$ Division of Sustainable Development, College of Science and Engineering, Hamad Bin Khalifa University, Qatar \\ Foundation, Doha, Qatar \\ ${ }^{2}$ Division of Engineering Management and Decision Sciences, College of Science and Engineering, Hamad Bin \\ Khalifa University, Qatar Foundation, Doha, Qatar \\ Correspondence to (talansari@hbku.edu.qa)
}

\begin{abstract}
Climate change is one of the most severe global challenges of the present generation. Variations in temperature and precipitation can seriously affect water energy, water and food (EWF) security. Assessment of the ground-based observation of the climatic parameters such as temperature and precipitation are vital for the overall decision-making process concerning energy, water and food security. In this study, temperature and precipitation data is investigated using the Mann Kendall, Pettitt and Watson tests and inter-annual variability assessment. Long-term temperature data indicates that the annual and seasonal temperature has increased significantly between 1987 and 2016. The mean temperature has increased by $1.02{ }^{\circ} \mathrm{C}$ over the period of observation. In contrast, the study determines that precipitation during the period of observation decreased by $-12.6 \mathrm{~mm}$. However, this decreasing trend is not statistically significant $(\mathrm{p}<0.05)$. Furthermore, total monthly precipitation is observed to be decreasing during the winter (December-January-February-DJF) while increasing in spring (March-April-May-MAM), summer (June-July-August-JJA) and autumn (September-October-November-SON). Despite the observed increases in the seasonal temperature during JJA, MAM and SON, the decreasing trend in winter precipitation is of more concern as most of the rainfall is received during DJF. These results have serious implications for EWF resources and the 'nexus' between them. Such integrated resource management approaches not only lower the risks of a one-dimensional decision-making process, it can also identify interdependencies, synergies, and trade-offs amongst the EWF sectors. As an outcome of the calculated trends, this study recommends measures to improve the overall resilience of EWF sectors and to adapt and mitigate the negative consequences of the changing climate faced by these sectors.
\end{abstract}

Keywords: Climate change, EWF nexus, Urbanization, Trends, Variability 


\section{Introduction}

Global warming has intensified and become more extreme throughout the latter half of the twentieth century caused by human activities ${ }^{1}$, rapid economic development, and urban expansion 2. In particular, because of the rise in atmospheric greenhouse gas concentrations, such as carbon dioxide ${ }^{3}$. Worldwide averaged terrestrial and sea surface temperature increased by $0.85^{\circ} \mathrm{C}$ during the period of observation 1880 to $2012^{4}$. Global land-based data analysis from weather stations also suggests that land surface temperature is rising. For instance, LaDochy et al. ${ }^{5}$ stated average warming of $0.99{ }^{\circ} \mathrm{C}$ in California for 50 years 1950-2000. Muslim and Błażejczyk ${ }^{6}$ applied a linear regression model and the Mann-Kendall test to evaluate inter-annual and long-term changes in temperature from 1941 to 2013 in Iraq and determined an increasing trend. Islam et al. ${ }^{7}$ examined temporal fluctuation in temperature over Saudi Arabia from 1981 to 2010 and concluded warming trends in most of the weather station with significant trends in spring and summer

seasons. Martinez et al. ${ }^{8}$ also reported long term increasing temperature trends in the mean minimum and maximum temperature over Florida between 1895-2009. Mikkonen et al. ${ }^{9}$ used a dynamic linear model to analyze mean temperature patterns in Finland and estimated that mean temperature rose by $2^{\circ} \mathrm{C}$ with an increased rate of $0.14^{\circ} \mathrm{C}$ per decade. Comparable encouraging results have been observed in China for 54 years (1960- 2013) ${ }^{10}$. Zhang et al. ${ }^{11}$ studied 52 weather stations data between 1950-2003 and reported significant warming trends in the Arabian Peninsula.

Precipitation has a key role in the climate system, particularly in hydrometeorology. There is a general agreement on the regional responses to climate change, the wet regions will become wetter while the dry regions will become drier under the influence of climate change ${ }^{12-14}$. For instance, Jones and Harris ${ }^{15}$ studied 223 weather stations in the UK using the linear regression test and reported an increase in winter, spring and autumn extreme precipitation events, while a decrease in short duration summer precipitation events. Brunetti et al. ${ }^{16}$ studied daily precipitation data of 7 weather stations in North-eastern Italy and determined a significant increase in extreme precipitation during 1920-1998. Nastos and Zerefos ${ }^{17}$ used the linear regression test to study 21 weather stations data in Greece and determined an increasing trend in the rate of extreme 
precipitation from 1957 to 2001. Mekis and Vincent ${ }^{18}$ reported an increment in the total precipitation in the fall and spring seasons, while a decline in the winter season during the period of 1950-2010 in Canada. Zolina ${ }^{19}$ applied a linear regression test to study precipitation trends in 5454 weather stations in Germany and found a general increase in extreme winter precipitation while a general decreasing trend in summer precipitation. Pujol et al. ${ }^{20}$ studied daily precipitation data of the 92 stations in the Mediterranean region of France over the period of observation 19452004, and reported a statistically significant increasing precipitation trend in the three out of seven regions. Using the Mann Kendall trend test, a significant increase was observed in precipitation in the western part of the Czech Republic ${ }^{21}$. Similarly, an upward trend in extreme rainfall intensities was observed during 1931-1970 and 1971-2007 in Cypress Nicosia ${ }^{22}$.

Such fluctuations in mean temperature and total precipitation are of serious concern to society, to the economy, to the environment and to the management of electricity, water and food supplies, which are necessary for the maintenance of life on earth. In a dynamic 'nexus' also known as Energy Water Food Nexus EWF, these three resources are deeply connected ${ }^{23-25}$. Water is needed at different stages of fossil fuels processing, power generation and thermal plants cooling, whereas energy is required for water pumping, distribution, filtration, desalination, water treatment and food production. Similarly, the agriculture sector uses a significant amount of water and energy, accounting for more than $70 \%$ of freshwater and $30 \%$ of the worldwide energy consumption ${ }^{26}$. Interdependencies and interconnectedness of the EWF nexus vary spatially depending on the availability of energy, food and water resources. Due to the strong interlinkages and interdependencies between energy, water and food sectors, there is a need to study their vulnerability to changes in climatic parameters like temperature and precipitation. The EWF nexus is especially important for countries situated in arid climates such as Qatar that have a disproportionate distribution of resources. For instance, the water sector in the state of Qatar is more dependent on the energy sector as most of the freshwater $(61 \%)$ is produced from seawater desalination which is powered by electricity ${ }^{27}$. With limited renewable freshwater resources and annual precipitation, most of the land is not suitable for conventional agriculture and the state of Qatar imports about $90 \%$ of its food, which has effects on its long-term food security ${ }^{28}$.

The purpose of this study is to investigate spatial and temporal variability in precipitation and temperature for annual and seasonal timescales and highlight the extent to which these climatic changes may affect the EWF nexus in the state of Qatar. In addition, this study is expected to 
increase the knowledge regarding the annual and seasonal distribution of temperature and precipitation and to fill the gap of the previous research as described above, where ${ }^{29}$ analysed data from one weather station. This study aims to increase the representation of Qatar's climate by using climatic data from six weather stations over a 30 year period. Outcomes of this study are expected to increase the understanding regarding floods, droughts, and risks faced the energy, water and food resources.

\section{Methods and Data}

\subsection{Climatic data}

The State of Qatar is situated at the eastern coast of the Arabian Peninsula, sharing a border with the Kingdom of Saudi Arabia to the south and encircled by the Arabian Gulf in all other directions. It has a land area of $11,571 \mathrm{~km}^{2}$, and it bulges about $160 \mathrm{~km}$ in the Persian Gulf. The state of Qatar is a fairly flat, its elevation varies from 5 to $107 \mathrm{~m}$ above sea level (Figure 1). Weather is hot and humid with erratic annual precipitation. 


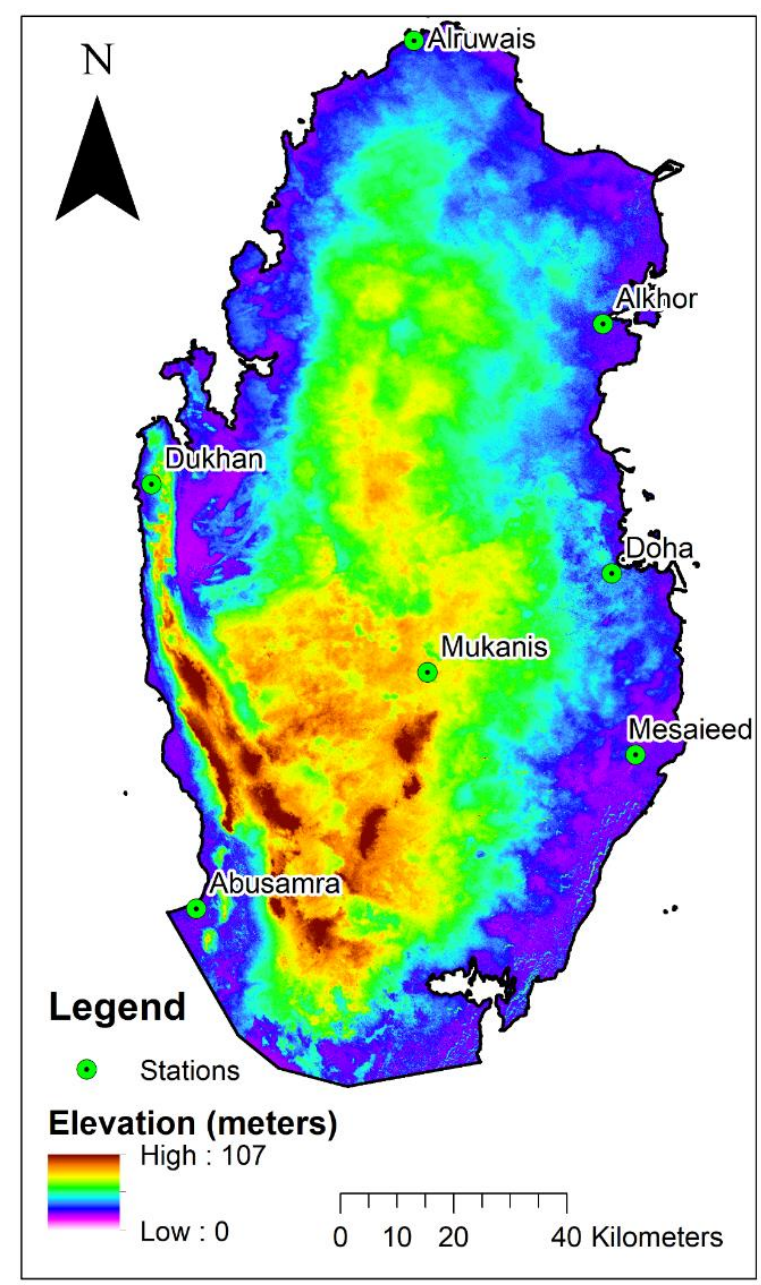

Figure 1. Digital Elevation Model DEM of the state of Qatar with weather stations location.

According to the Qatar meteorological department, 16 weather stations provide daily data on different climatic parameters such as temperature, precipitation, humidity, wind and solar radiation etc. However, due to less availability of long-term data, only 6 weather station data are used for the long-term analysis (Table 1). Daily mean temperature and daily total precipitation data area acquired from 1987 to 2016 . Although many of the weather stations have been installed recently, those weather stations will be selected which can cover data provision over 30 years. Table 1 below provides a detailed summary of the weather stations. 
Table 1. Location of the weather stations and dataset period.

\begin{tabular}{lllll}
\hline Weather station & Longitude & Latitude & Elevation $(\mathbf{m})$ & Data period \\
Doha & 51.51051 & 25.28232 & 12 & $1987-2016$ \\
Mesaieed & 51.54831 & 24.99424 & 06 & $1987-2016$ \\
Mukanis & 51.21765 & 25.12483 & 35 & $1987-2016$ \\
Dukhan & 50.77898 & 25.42424 & 31 & $1987-2016$ \\
Alruwais & 51.19646 & 26.12855 & 09 & $1987-2016$ \\
Alkhor & 51.49618 & 25.67839 & 14 & $1987-2016$ \\
\hline
\end{tabular}

\subsection{Mann-Kendall Trend Analysis}

The Mann-Kendall (MK) test ${ }^{30-32}$ is applied to detect a trend in time series of climatic and hydrological data. The MK statistic suggests whether a trend exhibit in the time series data and whether the trend is positive or negative. The MK test is often used as an investigative analysis to assess stations with major or large-scale variations. ${ }^{32}$. The MK test is non-parametric, indicating that it does not rely on knowledge of the sampled population distribution. The null hypothesis (H0) is that no trend is present in the data. The alternative assumption (Ha) is that a monotonic pattern is followed by the results. A monotonic pattern means that, over time, the trend is gradually going down or going up. The indicator of the strength of a trend is Kendall's tau (t). When the p-value is less than the alpha $=0.05$ significance level, a pattern is reported as statistically important. Likewise, if the $p$-value is greater or smaller than the alpha $=0.05$ significance level, a null hypothesis is rejected or accepted. The S statistic used for the Mann Kendall test is:

$$
s=\sum_{k=1}^{n-1} \sum_{j=k+1}^{n} \operatorname{sgn}\left(X_{j}-X_{k}\right)
$$

where $\mathrm{X}_{\mathrm{j}}$ and $\mathrm{X}_{\mathrm{k}}$ are the adjacent data values, $\mathrm{S}$ is the sum of positive or negative signs, $\mathrm{n}$ is the number of observations and variance can be calculated as;

$$
\operatorname{var}(S)=\frac{n(n-1)(2 n+5)}{18}
$$

\subsection{Durbin Watson Test}


The Mann-Kendall trend test needs that the correlation between the time series with itself with a given lag should not be significant. The existence of autocorrelation leads to an overestimation (underestimation) of the trend detection likelihood ${ }^{33} ;{ }^{34}$. It is suggested to test the data series for autocorrelation before applying the Mann-Kendall trend test. The Durbin-Watson test is applied to identify the autocorrelation in the residuals from a linear regression ${ }^{35}$.

$$
\varepsilon=\rho \varepsilon_{t-1}+u_{t}
$$

Where $p$ is the autocorrelation coefficient and $u$ is an error term. The null hypothesis $\left(\mathrm{H}_{0}\right)$ is that the errors are uncorrelated. The alternative hypothesis $\left(\mathrm{H}_{\mathrm{a}}\right)$ is that the errors are $\mathrm{AR}(\mathrm{p})$, while $\mathrm{p}$ is the order of autocorrelation.

$$
d=\frac{\sum_{2}^{T}\left(e_{t}-e_{t-1}\right)^{2}}{\sum_{1}^{T} e_{t}^{2}}
$$

The Durbin-Watson $d$ statistic equals 0 if there is an extreme positive serial correlation, two if there is no serial correlation, and four if there is an extreme negative serial correlation.

\subsection{Mann-Whitney-Pettitt Change Point Analysis}

The Pettitt's test is a nonparametric suggested by Pettitt in $1979^{36}$. Pettitt's test is applied to detect the time at which the change happens. It is frequently used to identify a single change-point in hydrological and climatic data series ${ }^{37}$. This test not only reveals occurrence time but also the magnitude of the change point. The null hypothesis $\left(\mathrm{H}_{0}\right)$ is the $\mathrm{T}$ variables follow one or more distributions that have the same location parameter (no change). The alternative hypothesis $\left(\mathrm{H}_{\mathrm{a}}\right)$ is that a change point exists in the data. The non-parametric statistic is defined as:

$$
K_{T}=\max \left|U_{t}, T\right|
$$

Where

$$
U t, T \sum_{i=1}^{t} \sum_{j=t+1}^{T} \operatorname{Sgn}\left(X_{i}-X_{j}\right)
$$

$\mathrm{Xi}$ and $\mathrm{Xj}$ are the adjacent data values, $\mathrm{n}$ is the number of observations. The change-point of the series is situated at $\mathrm{K}_{\mathrm{T}}$, if that the statistic is significant. 
The significance probability of $\mathrm{K}_{\mathrm{T}}$ is approximated for $\mathrm{p} \leq 0.05$ as:

$p \simeq 2 \exp \left(\frac{-6 K_{T}^{2}}{T^{3}+T^{2}}\right)$

\subsection{DIGITAL ELEVATION MODEL}

Shuttle Radar Topography Mission SRTM 30m digital elevation model is utilized for the delineation of the watershed. The 30m (1 arc-second) resolution SRTM DEM data was downloaded from https://earthexplorer.usgs.gov/. Downloaded tiles of the SRTM DEM were mosaicked and study area was extracted as a mask using ArcMap 10.4.

\section{Results and discussion}

\subsection{State-wide annual and seasonal climatic trends}

Mean temperature data from four weather stations from 1987-2016 were averaged to establish a state-wide representative mean annual temperature. Long-term temperature data indicates that the mean annual temperature in Qatar is $27.42{ }^{\circ} \mathrm{C}$ with significant variation between diurnal and seasonal temperature. Mean annual data are analysed using the Mann Kendall trend test with a confidence level of 95\%. Mann Kendal trend test analysis indicates a significant $(p<0.005)$ increase in the state-wide mean annual temperature over the period of observation (Figure 2). The Sen's slope estimates that mean temperature has increased by $1.02{ }^{\circ} \mathrm{C}$ over the last 30 years with $0.034^{\circ} \mathrm{C}$ per year increment. These warming trends are in agreement with the previous studies in Qatar ${ }^{29}$, Saudi Arabia ${ }^{7,38}$, Iran; ${ }^{39}$, and Kuwait ${ }^{40}$. Mann Pettit test indicates that a significant change in the annual temperature data in 1997. According to The Oceanic Niño Index (ONI) by the National Oceanic and Atmospheric Administration (NOAA), 1997-98 were strong La Nino years. 


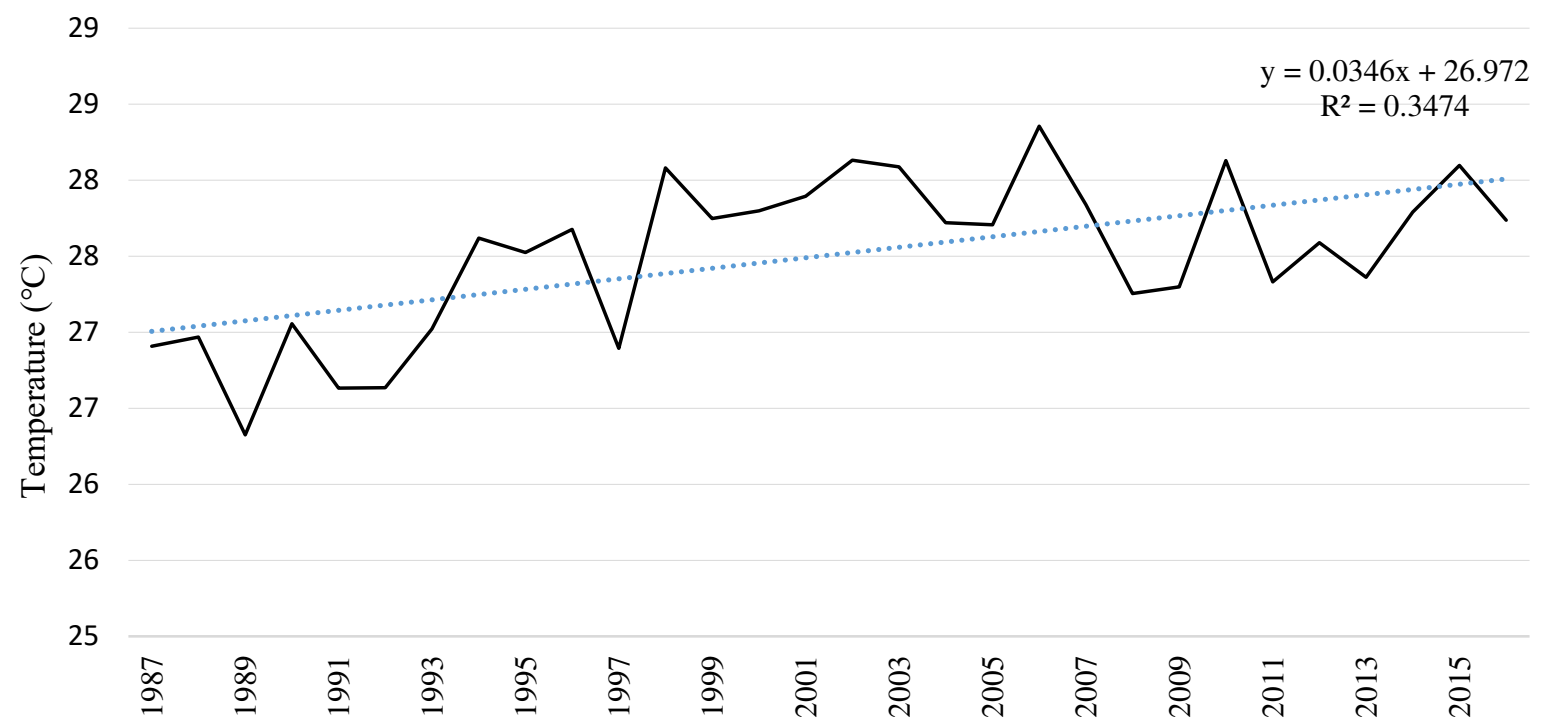

Figure 2. State-wide mean annual temperature in the state of Qatar from 1987-2016.

Precipitation data from four weather stations are also analysed for long-term trends using the Mann Kendall trend test with $95 \%$ confidence. State-wide long term total annual precipitation data indicates the precipitation is decreasing over the state of Qatar (Figure 3). It is determined that precipitation during the period of observation decreased by $-0.42 \mathrm{~mm}$ per year. However, this decreasing trend is not statistically significant $(\mathrm{p}<0.05)$. These drying trends are persistent with the subtropical drier projection (Held et al., 2006). More recently, similar dry episodes are observed in East Africa ${ }^{41-45}$.

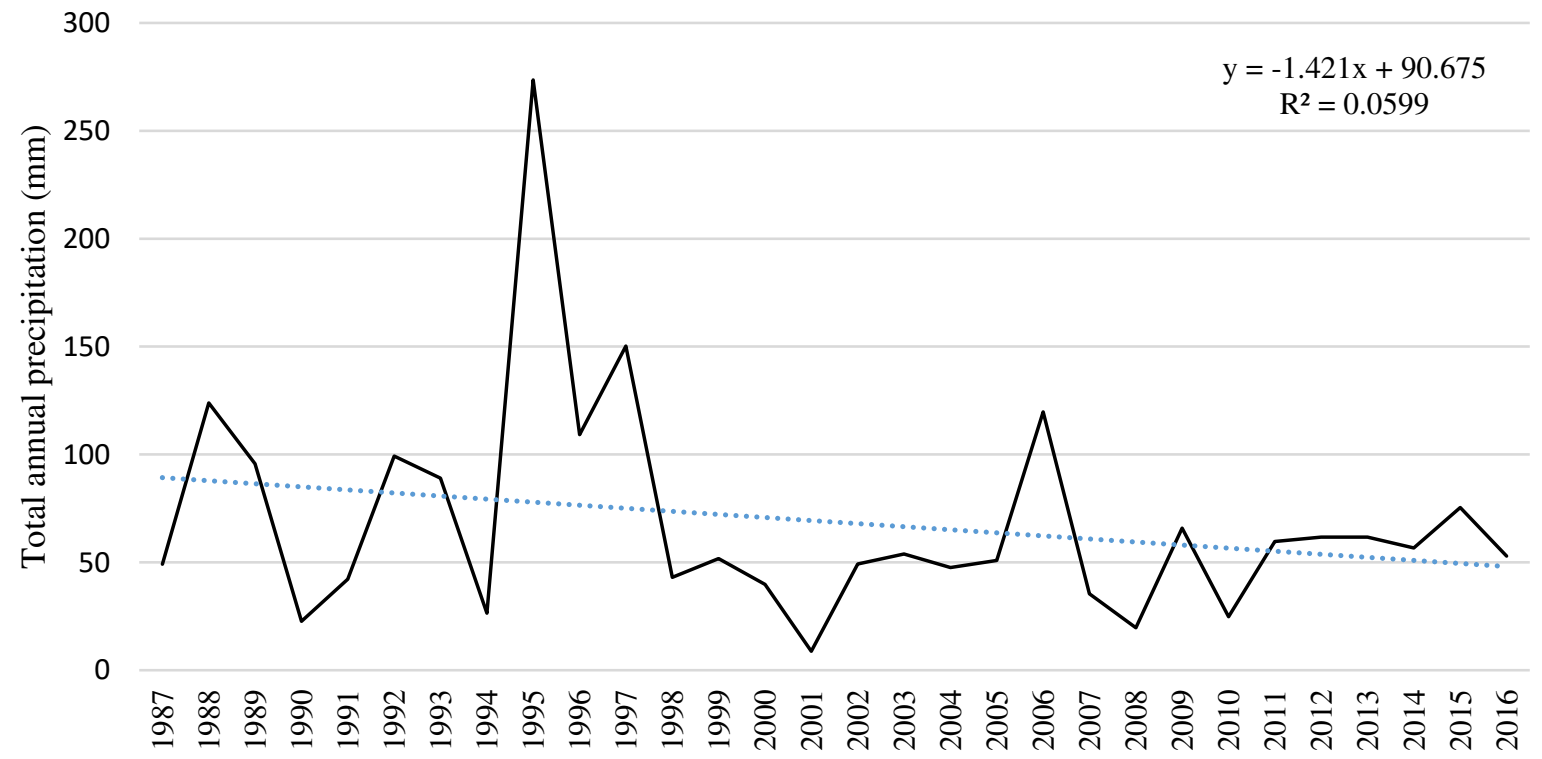


Figure 3. State-wide total annual precipitation in the state of Qatar from 1987-2016.

\subsection{State-wide seasonal climatic trends}

Mean temperature and total monthly precipitation data from six weather stations are divided into seasonal sub-set, for example, winter (December, January, February-DJF), summer (June, July, August-JJA), spring (March, April, May-MAM) and autumn (September, October, NovemberSON) seasons. Seasonal data analysis demonstrates that mean monthly temperature during DJF ( $\tau$ $=0.173, \mathrm{~S}=0.016, \mathrm{p}<0.01), \operatorname{MAM}(\tau=0.358, \mathrm{~S}=0.02, \mathrm{p}<0.0001)$, JJA $(\tau=0.362, \mathrm{~S}=0.011$, $\mathrm{p}<0.0001)$, and $\operatorname{SON}(\tau=0.335, \mathrm{~S}=0.014, \mathrm{p}<0.0001)$, has increased significantly $(\mathrm{p}<0.05)$ over the 30 years periods of observation. As indicated by the Mann Kendall tau value increasing trends are comparatively prominent during summer, spring and autumn (Figure 4).
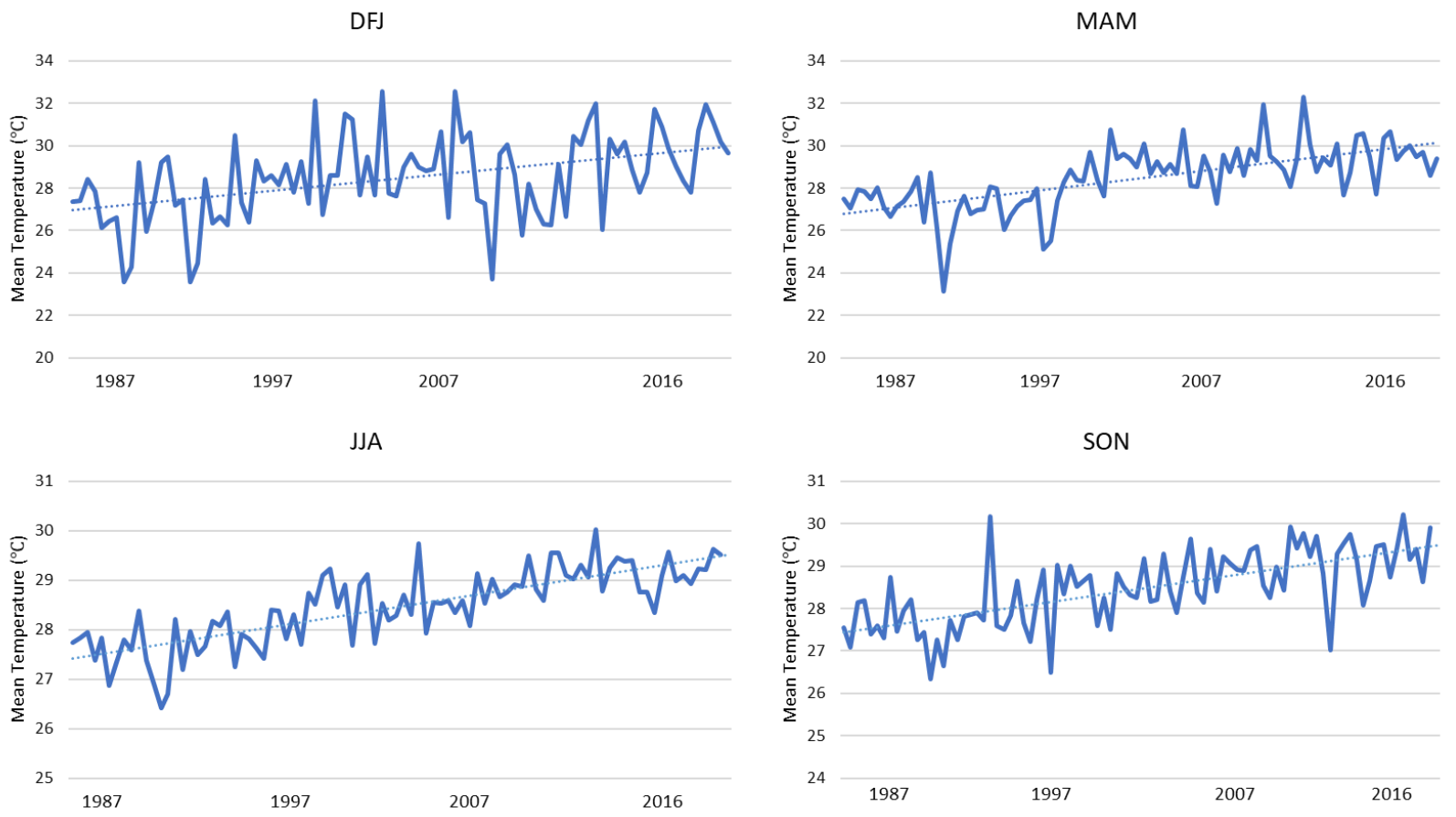

Figure 4. State-wide seasonal temperature trends 1987-2016.

Similarly, total monthly precipitation is analysed for seasonal trends using the Mann Kendall trend test with $95 \%$ confidence. Most of the precipitation occurring during DJF and MAM followed by SON and JJA. JJA is usually dry with zero precipitation; however, in the recent decade 
precipitation during JJA is increasing. Based on the Mann Kendall trend test, a statistically significant increment in the total monthly precipitation data is observed during JJA $(\tau=0.453$, $\mathrm{S}=0, \mathrm{p}<0.0001)$ and $\mathrm{SON}(\tau=0.314, \mathrm{~S}=0, \mathrm{p}<0.0001)$ (Figure 5). In contrast a non-significant downward trend in the total monthly precipitation is found during DJF $(\tau=-0.109, S=-0.045$, $\mathrm{p}>0.05)$, while a non-significant increasing trend is observed for MAM $(\tau=0.047, S=0, p>0.05)$.
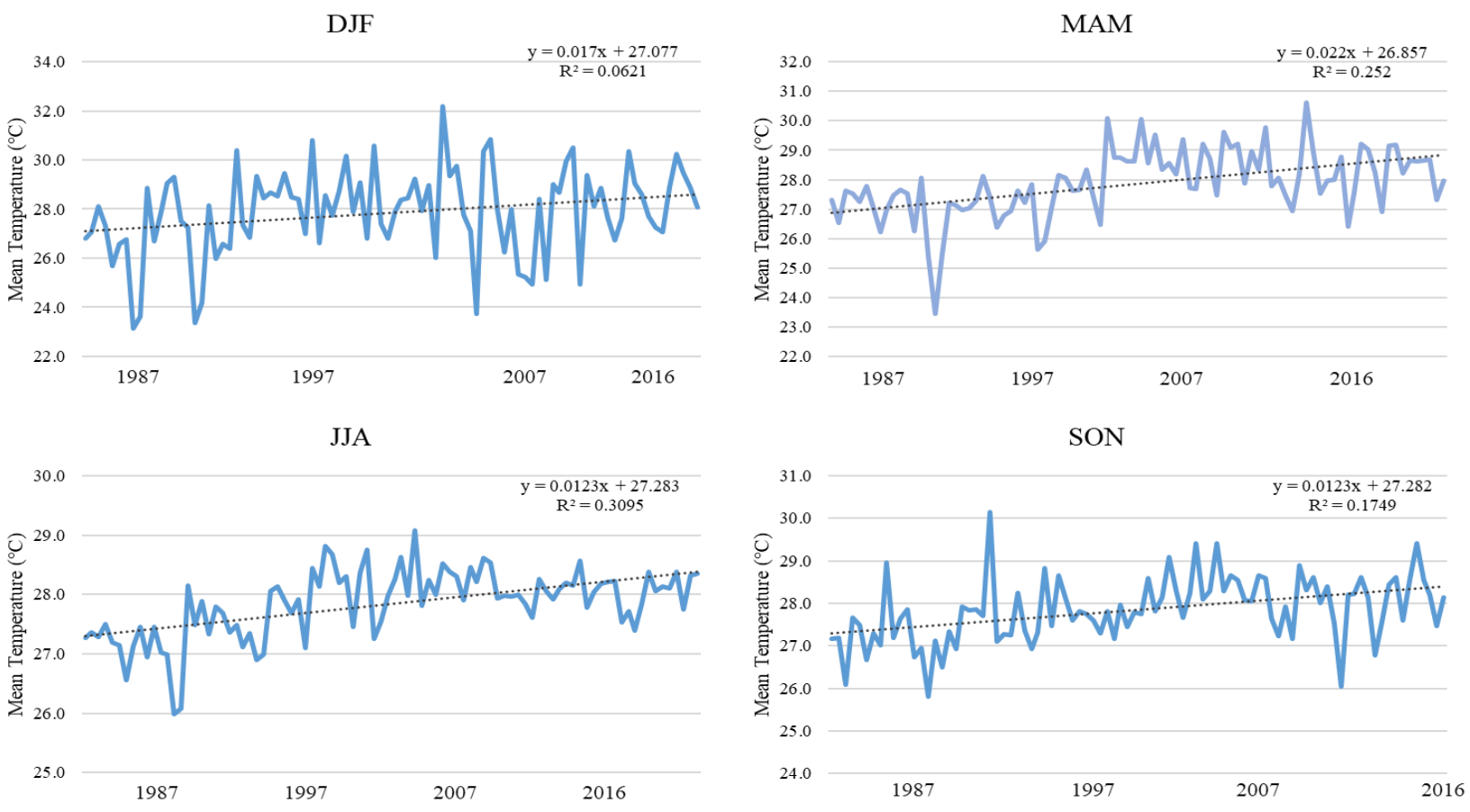

Figure 5. State-wide seasonal precipitation trends 1987-2016.

\subsection{Station-wise annual trends}

Precipitation and temperature data of six weather stations are analysed for long-term trends and spatial variability. Long-term data analysis indicates that four $(66 \%)$ weather stations exhibit statistically significant increasing trends, while two weather stations namely, Dukhan and Mukanis demonstrate increasing but non-significant upward trends in the mean annual temperature (Figure 6). It is determined that weather stations situated at the eastern southern coastal areas experience significant increment in the mean annual temperature, while the temperature at the western coastal areas such as Dukhan is increasing, however, the trend is not statistically significant. 
In contrast to the increasing mean annual temperature, the annual total precipitation is decreasing at all weather stations, however, the only significant decrease in the total annual precipitation is found at Al-khor weather station (Figure 6).
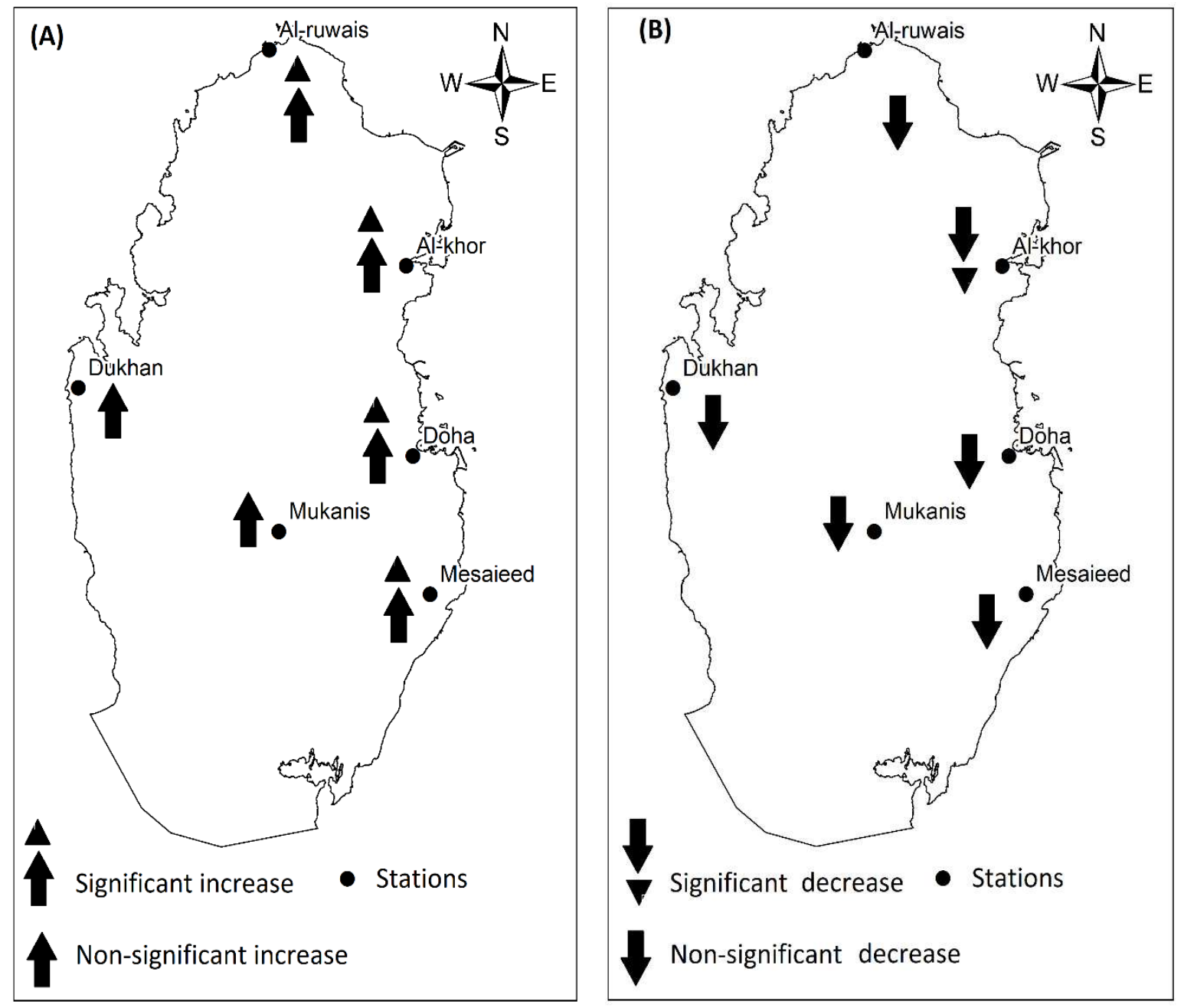

Figure 6. Station wise spatial variability in mean annual temperature (A) and total annual precipitation (B).

\subsection{Seasonal station wise spatial variability}

Data from six weather stations are analysed for seasonal trends, winter-DJF, spring-MAM, summer-JJA and autumn-SON. All weather stations indicate an increased temperature in the seasonal mean monthly temperature. However, $50 \%$ of weather stations namely, Doha, Al-ruwais and Mukanis indicate a significant increase during DJF. The number of weather stations with a significant increase in the monthly temperature further increased to $66.67 \%$ during MAM, JJA and SON (Figure 7). Most of these weather stations are installed at the eastern and southern coastal 
areas. In contrast, both the Al- Khor station installed at the eastern coastal line and Dukhan weather station, which is situated at the western coastal line is exhibiting non-significant increasing trends. This could be attributed to the geographic, climatic and anthropogenic changes in those areas.
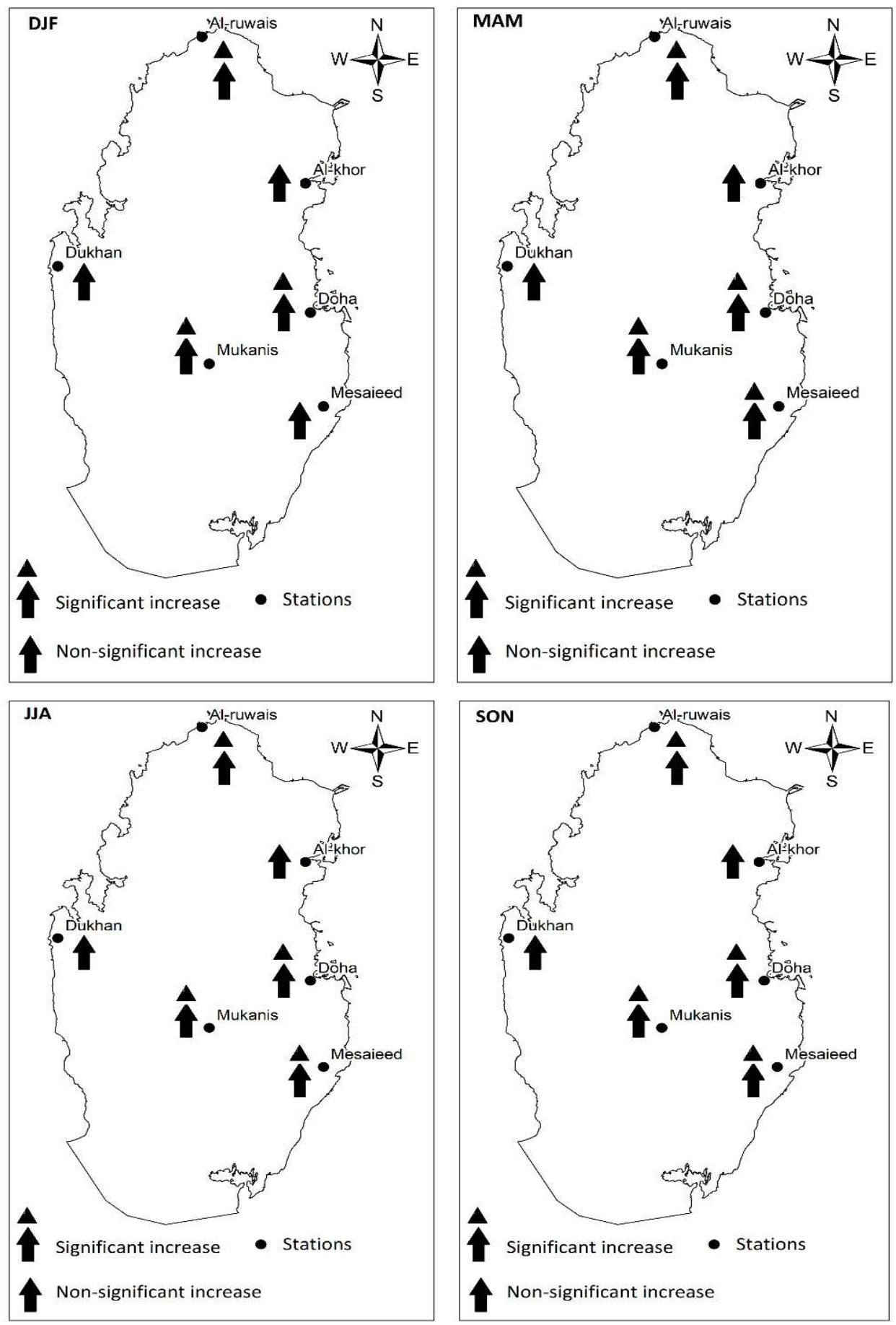

Figure 7. Station wise seasonal temperature trends. 
All six weather stations are also investigated for seasonal precipitation variation. Mann Kendall trend test indicated great variability in seasonal temperature in DJF and MAM as compared to JJA and SON. In DJF, none of the weather stations indicates a statistically significant increase in the monthly precipitation however, a general non-significant decreasing trend is observed at five stations. As the temperature increases with the early warming in later February, monthly precipitation tends to increase with a significant increase at Dukhan weather station. In JJA 80\% of stations demonstrated a statistically significant increase in the total monthly precipitation. Similarly, $83 \%$ of stations indicated a significant upward tendency in the total monthly precipitation during SON. Though monthly precipitation is increasing significantly in JJA and SON, however, a significant amount of precipitation is received in DJF. Thus, decreasing trends in DJF is of importance as compared to the observed significant increases in MAM, JJA and SON (Figure 8). 

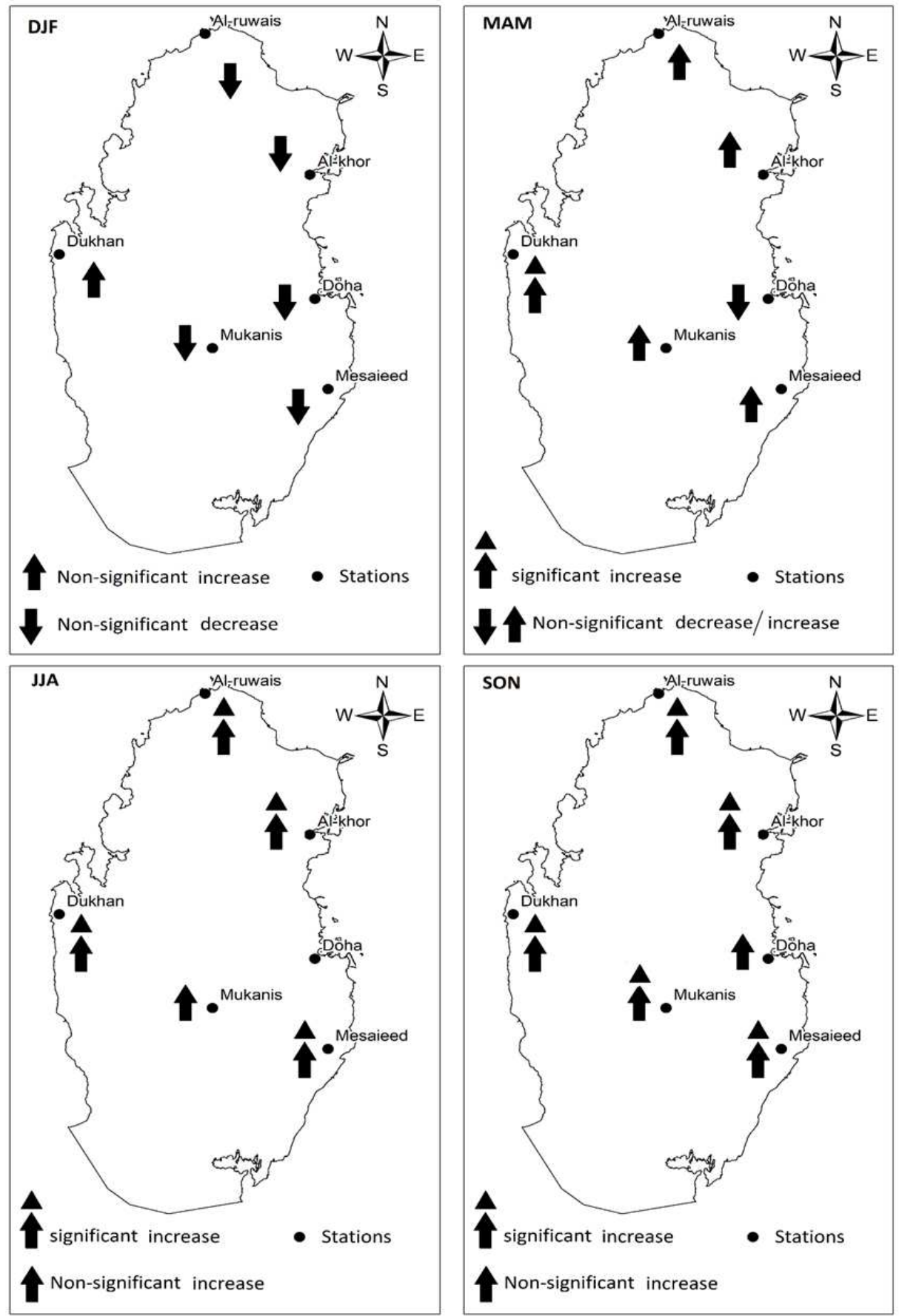

Figure 8. Station wise seasonal precipitation trends. 


\section{Geo-statistical analysis}

Kriging assumes that at least some of the spatial variation observed in natural phenomena can be modelled by random processes with spatial autocorrelation and require that the spatial autocorrelation be explicitly modelled. Kriging techniques can be used to describe and model spatial patterns, predict values at unmeasured locations, and assess the uncertainty associated with a predicted value at the unmeasured locations. Kriging modelling of temperature indicates that urbanised areas are comparatively hotter based on the data from Doha and Mukanis as compared to the northern and southern areas. In contrast, most of the rainfall is in northern coastal areas such as Al-Ruwais followed by eastern coastal such as Doha and Al-Khor (Figure 9).
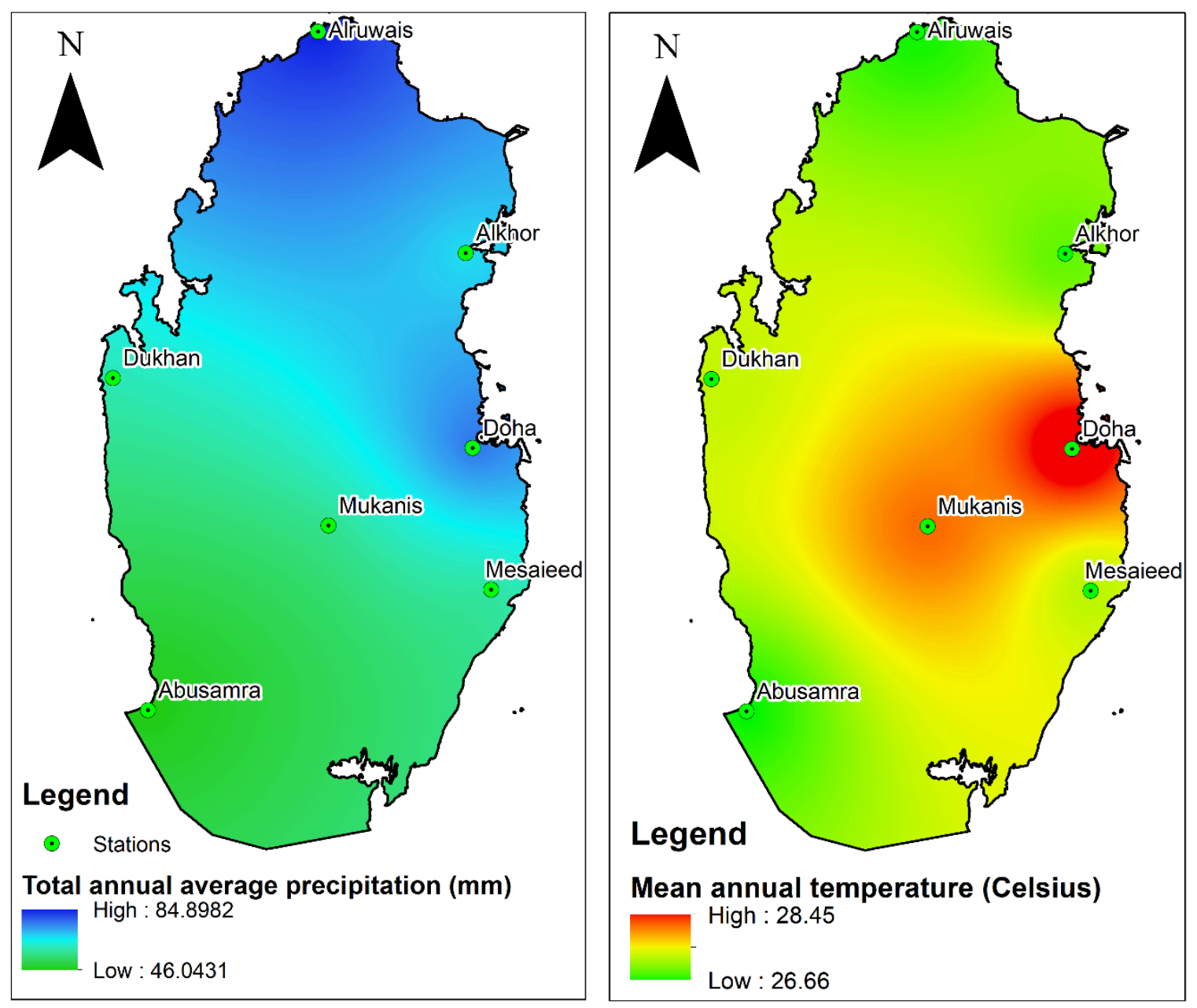
Figure 9. Spatial distribution of total annual precipitation and mean annual temperature over the state of Qatar.

\section{Implications for the Energy Water Food nexus in Qatar}

Demand for energy, water and food is increasing not only in the state of Qatar but globally. The world energy use will increase by approximately 50\% between 2018 and 2050 with the estimate for the industrial sector growth more than 30\%, transportation sector energy consumption by $40 \%$ and power generation by $79 \%{ }^{46}$. Similarly, worldwide freshwater demand will increase substantially in industry, agriculture and domestic sectors in the coming decades. Demands $n$ the Industrial and domestic sectors will increase rapidly than in the agricultural sector however demand for freshwater in the agriculture will remain the biggest ${ }^{47}$. Worldwide freshwater demand in agriculture sector is projected to increase by up to $60 \%$ by $2025^{48}$. A substantial volume of water is also used in the energy sector and estimate has suggested that an increment of $20 \%$ over the period $2010-2035^{49}$, and even a further extent $85 \%$ by $2050^{50}$. Domestic freshwater demand is projected to grow significantly by 2050 in all the over the world ${ }^{49}$. Moreover, to sustain the future increasing population, there is a need to supply about $50 \%$ additional food by $2050^{26}$.

With limited renewable freshwater options and erratic annual precipitation in Qatar, fossil-based energy-intensive desalination technologies fulfil domestic and industrial water consumption needs in the state of Qatar. A major position of water is produced from seawater desalination (61\%), followed by groundwater abstraction $(25 \%)$ and treated wastewater $(13 \%)$. The total annual water production and reuse were 912 million $\mathrm{m}^{3}$ in $2016^{27}$. A major portion of this water is consumed by households $(36.8 \%)$ followed by agriculture (33.8\%), commercial (15\%) and about $13 \%$ by the government sector. At current trends, future resource demand will result in significant increases in global GHG emissions across the globe and Qatar included. According to the World Resource Institute, energy produces more than $94 \%$ of the global GHGs emissions in the state of Qatar ${ }^{51}$, in which approximately $87.55 \mathrm{MtCO}_{2} \mathrm{e}$ was released from the energy sector in 2016 . In contrast to global emissions trends, emissions from the agriculture sector were the least amongst the sectors with $0.76 \mathrm{MtCO}_{2} \mathrm{e}$. This is mainly because most of the land is not suitable for conventional agriculture and the food sector is dependent on imports (Figure 10). 


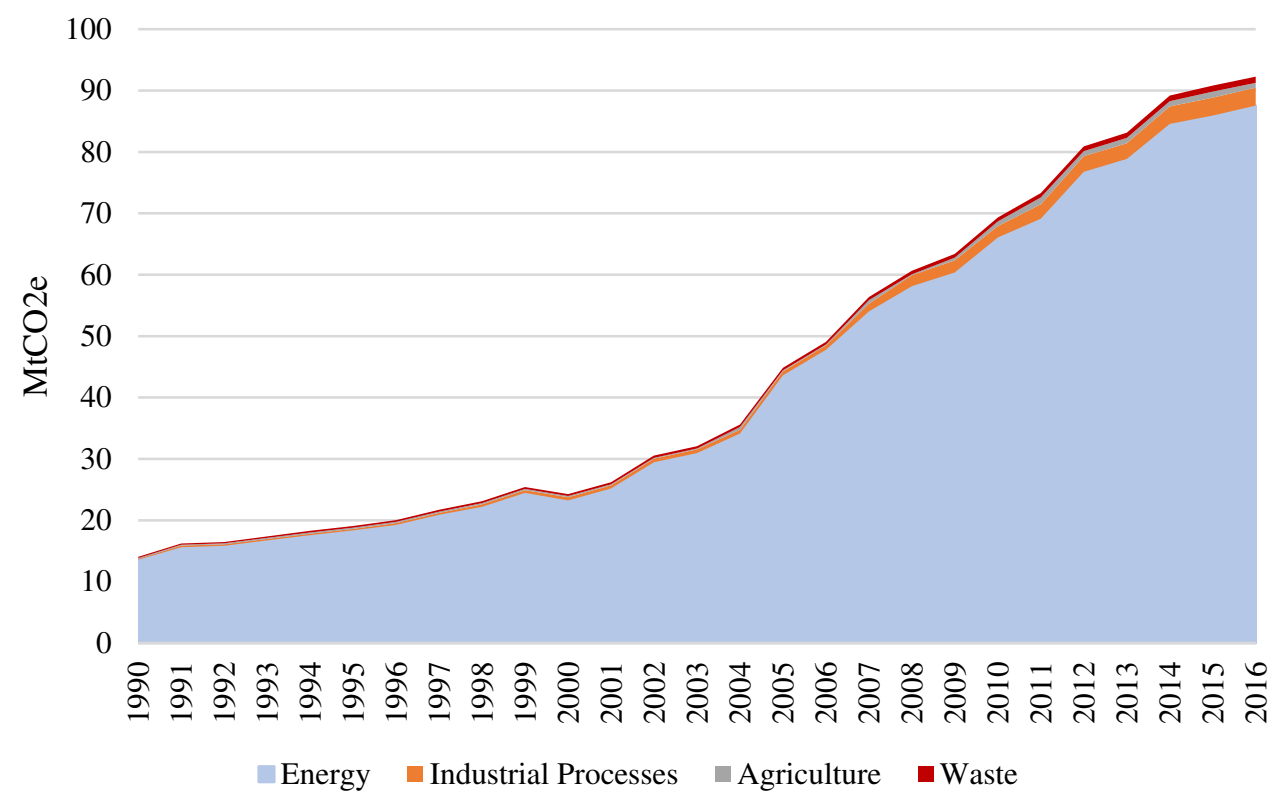

Figure 10. GHGs emission in the state of Qatar by sector from 1990 to 2016. Adapted from (WRI, 2016).

Water and food sectors are heavily dependent on the climate and weather conditions, making them particularly susceptible to climate change. Changes in temperature and precipitation is a significant outcome of climate change and can affect energy, food and water resources. The observed significant fluctuations in the mean temperature and precipitation will likely affect the EWF nexus in the decades to come. In the context of Qatar, there is a strong interdependency between energy and water; food and water; energy and food (Figure 11). The current water supply system is $100 \%$ dependent on the continuous supply of energy for desalination, pumping, transportation, storage and wastewater treatment. According to the Planning and Statistics Authority, $61 \%$ of water is produced from seawater desalination, $25 \%$ from groundwater and $13 \%$ is treated wastewater ${ }^{27}$, all of which require energy for operation. The observed significant increase in the mean temperature will affect the evapotranspiration rate, which is affecting water supply from the current three main sources (desalination, groundwater and wastewater treatment). Evapotranspiration is a key factor of the global hydrological and energy cycle. A change in climate and weather parameters will cause a substantial change in evapotranspiration ${ }^{52}$. Changes in evaporation will affect the soil moisture content and groundwater recharge. Rising temperature increases evaporative demand over land, which limits the amount of water to replenish groundwater ${ }^{53}$. In a recent study, a 
decrease in groundwater storage is has been observed in seven mid-latitude aquifers ${ }^{54}$. Besides, to increase the existing water supply share of desalination, groundwater and wastewater due to increased evapotranspiration caused by an increment in the mean temperature, will require more energy as desalination, groundwater pumping and wastewater treatment runs on electricity. In addition, water demand will increase in power plants and desalination plants for cooling if the increasing trend in mean temperature prevails in the future. Worldwide power generation is responsible for $\sim 10 \%$ of total water withdrawals and $\sim 3 \%$ of total water use ${ }^{50}$. Water withdrawal differs spatially depending on the utilization of energy generation technologies. For instance, in the US and Western Europe, around 50\% of water withdrawals accounts for energy production, mainly for cooling purposes ${ }^{55}$. Though, in China, nearly $84 \%$ of total freshwater withdrawals are for thermoelectric power generation ${ }^{56}$. Furthermore, power plants, solar cells and desalination power plant's efficiency are likely to be affected by changes in temperature. Thought, the state of Qatar imports the majority of its food, changes in the mean temperature will likely affect local crop rotation and agricultural yield. Furthermore, local meat and fish farming businesses will also be affected.

The observed reduction in the total annual rainfall is likely to affect groundwater recharge, water supply to the agriculture sector, agricultural yield. A decrease in groundwater will put pressure either to dig deeper or to produce more water through seawater desalination. This will possibly increase energy demand in the water and food sectors. In addition, less frequent rainfall or less rainfall can affect solar power efficiency as rainfall washes off dust from the solar panels (Figure $11)$. 


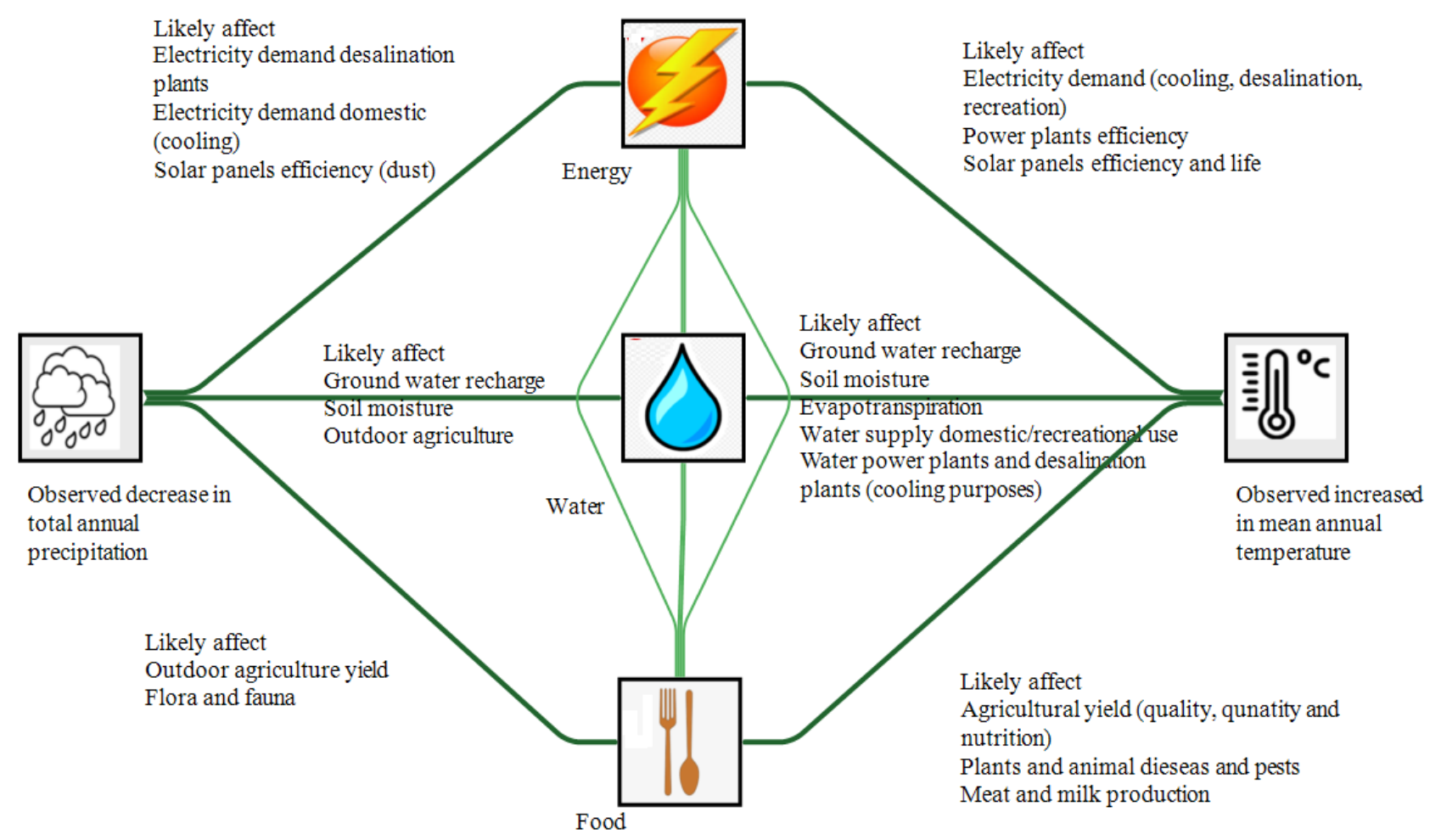

Figure 11. Possible impacts of observed climatic changes on the EWF nexus.

Based on the findings following measures are recommended to reduce the risks imposed by changes in temperature and precipitation to the energy, water and food security:

- Implement holistic and integrated approaches like EWF nexus in the decision-making process;

- Increase water efficiency in agriculture and thermal power plants;

- Increase energy efficiency in agriculture, desalination and wastewater treatment;

- Increase wastewater treatment and reuse;

- Diversification of power generation thermal, solar and wind;

- Increase proportion of protected/indoor agriculture and vertical farming;

- Encourage local food production through incentives;

- Enhance energy and water conservation measures;

- Enhance power plant and desalination plant efficiency;

- Rainwater harvest

- Increase in the urban green spaces (rooftop gardens, parks, buffer zones); 
- Use of reflective construction materials to reduce urban heat island effect;

\section{Conclusion}

This study examines trends of data from seven weather stations and illustrates changes in extreme temperature and precipitation for the period 1987-2016. The results demonstrate statistically significant and spatially non-coherent, trends in temperature corresponding to a warming trend in the state of Qatar. Despite the small size of the peninsula, considerable spatial variability exists among the weather stations. For instance, the eastern side of the peninsula is significantly warming as compared to the northern and western coastal areas. However, for rainfall decreasing trends are almost homogenous among the weather stations. On the other hand, seasonal temperature trends are less homogenous during DJF and MAM as compare to JJA and SON.

With increasing population, urbanisation and economic and technological development, there is continuous pressure on energy, water and food resources. In addition, climate change, which can cause variations in temperature and total annual precipitation, is one of the greatest risks to energy, water and food security. The observed significant increase in the mean temperature will affect the evapotranspiration rate and soil moisture in outdoor agriculture, which will likely increase the water supply-demand for irrigation. In addition, as water demand in agriculture and recreational activities increases due to increased evapotranspiration, energy demand will also increase to abstract more groundwater and to treat wastewater. Similarly, water demand will increase in power plants and desalination plants for cooling if the increasing trend in mean temperature prevails in the future. Furthermore, power plants, solar cells and desalination power plants efficiency are likely to be affected by changes in temperature and precipitation. Changes in the mean temperature and total precipitation will likely affect local crop rotation and agricultural yield. On the other hand, reduction in the annual rainfall will affect natural groundwater recharge making groundwater more saline. As a result, energy will be needed to treat groundwater before making it available for irrigation and recreational purposes Thus, informed smart decision-making needs to be introduced in the planning, policy and implementation stages of future projects dealing with the EWF nexus. Thought the present study is conducted using a long term 30 years ground-based data this can be

further improved by increasing the temporal resolution of the data. There also need to investigate and project variation in the climatic parameters like precipitation and temperature under different scenarios using high resolution regional and global climate models. 


\section{References}

1. Zwiers, F. W., Zhang, X. \& Feng, Y. Anthropogenic influence on long return period daily temperature extremes at regional scales. J. Clim. 24, 881-892 (2011).

2. Avila, F. B., Pitman, A. J., Donat, M. G., Alexander, L. V \& Abramowitz, G. Climate model simulated changes in temperature extremes due to land cover change. J. Geophys. Res. Atmos. 117, (2012).

3. Karl, T. R. et al. Weather and climate extremes in a changing climate. (2008).

4. IPCC. CLIMATE CHANGE 2013 Climate Change 2013 Edited by. Researchgate.Net (2013).

5. LaDochy, S., Medina, R. \& Patzert, W. Recent California climate variability: spatial and temporal patterns in temperature trends. Clim. Res. 33, 159-169 (2007).

6. Muslih, K. D. \& Błażejczyk, K. The inter-annual variations and the long-term trends of monthly air temperatures in Iraq over the period 1941-2013. Theor. Appl. Climatol. 130, 583-596 (2017).

7. Nazrul Islam, M., Almazroui, M., Dambul, R., Jones, P. D. \& Alamoudi, A. O. Long-term changes in seasonal temperature extremes over Saudi Arabia during 1981-2010. Int. J. Climatol. 35, 1579-1592 (2015).

8. Martinez, C. J., Maleski, J. J. \& Miller, M. F. Trends in precipitation and temperature in Florida, USA. J. Hydrol. 452, 259-281 (2012).

9. Mikkonen, S. et al. Trends in the average temperature in Finland, 1847-2013. Stoch. Environ. Res. Risk Assess. 29, 1521-1529 (2015).

10. Zhou, B., Xu, Y., Wu, J., Dong, S. \& Shi, Y. Changes in temperature and precipitation extreme indices over China: analysis of a high-resolution grid dataset. Int. J. Climatol. 36, 1051-1066 (2016).

11. Zhang, X. et al. Trends in Middle East climate extreme indices from 1950 to 2003. J. Geophys. Res. Atmos. 110, (2005).

12. Chou, C. et al. Increase in the range between wet and dry season precipitation. Nat. Geosci. 6, 263-267 (2013).

13. Chou, C., Neelin, J. D., Chen, C.-A. \& Tu, J.-Y. Evaluating the "rich-get-richer" mechanism in tropical precipitation change under global warming. J. Clim. 22, 1982-2005 (2009).

14. Feng, H. \& Zhang, M. Global land moisture trends: drier in dry and wetter in wet over land. Sci. Rep. 5, 18018 (2015).

15. Jones, P. \& Harris, I. CRU TS3. 21: Climatic Research Unit (CRU) Time-Series (TS) version 3.21 of high resolution gridded data of month-by-month variation in climate (Jan. 1901-Dec. 2012). NCAS Br. Atmos. Data Cent. (2013).

16. Brunetti, M., Maugeri, M. \& Nanni, T. Changes in total precipitation, rainy days and extreme events in northeastern Italy. Int. J. Climatol. A J. R. Meteorol. Soc. 21, 861-871 (2001).

17. Nastos, P. T. \& Zerefos, C. S. Decadal changes in extreme daily precipitation in Greece. (2008).

18. Mekis, É. \& Vincent, L. A. An overview of the second generation adjusted daily precipitation dataset for trend analysis in Canada. Atmosphere-Ocean 49, 163-177 (2011).

19. Zolina, O. Changes in intense precipitation in Europe. Chang. flood risk Eur. 10, 97-119 
(2012).

20. Pujol, N., Neppel, L. U. C. \& Sabatier, R. Regional tests for trend detection in maximum precipitation series in the French Mediterranean region. Hydrol. Sci. J. 52, 956-973 (2007).

21. Kyselý, J. \& Beranová, R. Climate-change effects on extreme precipitation in central Europe: uncertainties of scenarios based on regional climate models. Theor. Appl. Climatol. 95, 361-374 (2009).

22. Pashiardis, S. \& Michaelides, S. Implementation of the standardized precipitation index (SPI) and the reconnaissance drought index (RDI) for regional drought assessment: a case study for Cyprus. Eur. Water 23, 57-65 (2008).

23. Govindan, R. \& Al-Ansari, T. Computational decision framework for enhancing resilience of the energy, water and food nexus in risky environments. Renew. Sustain. Energy Rev. 112, 653-668 (2019).

24. Al-Ansari, T., Govindan, R., Korre, A., Nie, Z. \& Shah, N. An energy, water and food nexus approach aiming to enhance food production systems through CO2 fertilization. Computer Aided Chemical Engineering vol. 43 (Elsevier Masson SAS, 2018).

25. Namany, S., Al-Ansari, T. \& Govindan, R. Sustainable energy, water and food nexus systems: A focused review of decision-making tools for efficient resource management and governance. J. Clean. Prod. 225, 610-626 (2019).

26. FAO, F. The future of food and agriculture-Alternative pathways to 2050. (2018).

27. PSA. National Statistics. Planning and Statistics Authority vol. 24 59-82 https://www.psa.gov.qa/en/statistics1/Pages/default.aspx (2016).

28. Mustafa, S. A.-A. Growing food pyramids in the sand: how sustainable are Qatar's selfsufficiency and foreign agro-investment policies? (2017).

29. Cheng, W. L., Saleem, A. \& Sadr, R. Recent warming trend in the coastal region of Qatar. Theor. Appl. Climatol. 128, 193-205 (2017).

30. Mann, H. B. Nonparametric tests against trend. Econom. J. Econom. Soc. 245-259 (1945).

31. Kendall, M. Multivariate analysis. (Charles Griffin, 1975).

32. Hirsch, R. M. \& Slack, J. R. A nonparametric trend test for seasonal data with serial dependence. Water Resour. Res. 20, 727-732 (1984).

33. Wu, Z. et al. The modulated annual cycle: an alternative reference frame for climate anomalies. Clim. Dyn. 31, 823-841 (2008).

34. Rivard, C. \& Vigneault, H. Trend detection in hydrological series: when series are negatively correlated. Hydrol. Process. An Int. J. 23, 2737-2743 (2009).

35. Watson, G. S. \& Durbin, J. Exact tests of serial correlation using noncircular statistics. Ann. Math. Stat. 446-451 (1951).

36. Pettitt, A. N. A non-parametric approach to the change-point problem. J. R. Stat. Soc. Ser. C (Applied Stat. 28, 126-135 (1979).

37. Bilal, H., Chamhuri, S., Mokhtar, M. Bin \& Kanniah, K. D. Recent snow cover variation in the Upper Indus Basin of Gilgit Baltistan, Hindukush Karakoram Himalaya. J. Mt. Sci. (2019) doi:10.1007/s11629-018-5201-3.

38. Almazroui, M., Dambul, R., Islam, M. N. \& Jones, P. D. Atmospheric circulation patterns in the Arab region and its relationships with Saudi Arabian surface climate: a preliminary assessment. Atmos. Res. 161, 36-51 (2015).

39. Marofi, S., Sohrabi, M. M., Mohammadi, K., Sabziparvar, A. A. \& Abyaneh, H. Z. Investigation of meteorological extreme events over coastal regions of Iran. Theor. Appl. 
Climatol. 103, 401-412 (2011).

40. Nasrallah, H. A., Nieplova, E. \& Ramadan, E. Warm season extreme temperature events in Kuwait. J. Arid Environ. 56, 357-371 (2004).

41. Lyon, B. \& DeWitt, D. G. A recent and abrupt decline in the East African long rains. Geophys. Res. Lett. 39, (2012).

42. Liebmann, B. et al. Understanding recent eastern Horn of Africa rainfall variability and change. J. Clim. 27, 8630-8645 (2014).

43. Hoell, A., Hoerling, M., Eischeid, J., Quan, X.-W. \& Liebmann, B. Reconciling theories for human and natural attribution of recent East Africa drying. J. Clim. 30, 1939-1957 (2017).

44. Liebmann, B. et al. Climatology and interannual variability of boreal spring wet season precipitation in the eastern Horn of Africa and implications for its recent decline. J. Clim. 30, 3867-3886 (2017).

45. Wainwright, C. M. et al. 'Eastern African Paradox' rainfall decline due to shorter not less intense Long Rains. npj Clim. Atmos. Sci. 2, 34 (2019).

46. IEA. CO2 status report. IEA (International Energy Agency) Paris, Fr. (2019).

47. WWDR. 2018 UN World Water Development Report, Nature-based Solutions for Water. (2018).

48. Alexandratos, N. \& Bruinsma, J. World agriculture towards 2030/2050: the 2012 revision. (2012).

49. Wada, Y. et al. Modeling global water use for the 21st century: The Water Futures and Solutions (WFaS) initiative and its approaches. Geosci. Model Dev. 9, 175-222 (2016).

50. IEA. Water energy nexus-Excerpt from the world energy outlook 2016. (2016).

51. WRI. Agri-food markets in Qatar: Drivers, trends, and policy responses. Historical GHG Emissions vol. 12 https://www.climatewatchdata.org/ghg-

emissions?breakBy=sector\&gases=all-ghg (2016).

52. Abtew, W. \& Melesse, A. Evaporation and evapotranspiration: measurements and estimations. (Springer Science \& Business Media, 2012).

53. Berg, A. et al. Land-atmosphere feedbacks amplify aridity increase over land under global warming. Nat. Clim. Chang. 6, 869-874 (2016).

54. Wu, W.-Y. et al. Divergent effects of climate change on future groundwater availability in key mid-latitude aquifers. Nat. Commun. 11, 3710 (2020).

55. EEA. Water resources across Europe - confronting water scarcity and drought (EEA Report No. 2). Eur. Environ. Agency (EEA), Off. Off. Publ. Eur. Communities (OPOCE), Copenhagen, Denmark (2009).

56. Qin, Y., Curmi, E., Kopec, G. M., Allwood, J. M. \& Richards, K. S. China's energy-water nexus-assessment of the energy sector's compliance with the "3 Red Lines" industrial water policy. Energy Policy 82, 131-143 (2015).

\section{Acknowledgement}

This research is supported by the Qatar National Research Fund proposal (NPRP11S-0107180216).

\section{Author contributions}


H.B.: data download, data evaluation, data analysis, paper writing.: R.G.: data evaluation, data analysis, review. T.A.: data provision, supervision, review, editing.

\section{Competing interests}

The authors declare no competing interests. Additional information Correspondence and requests

for materials should be addressed to T.A. 
Figures
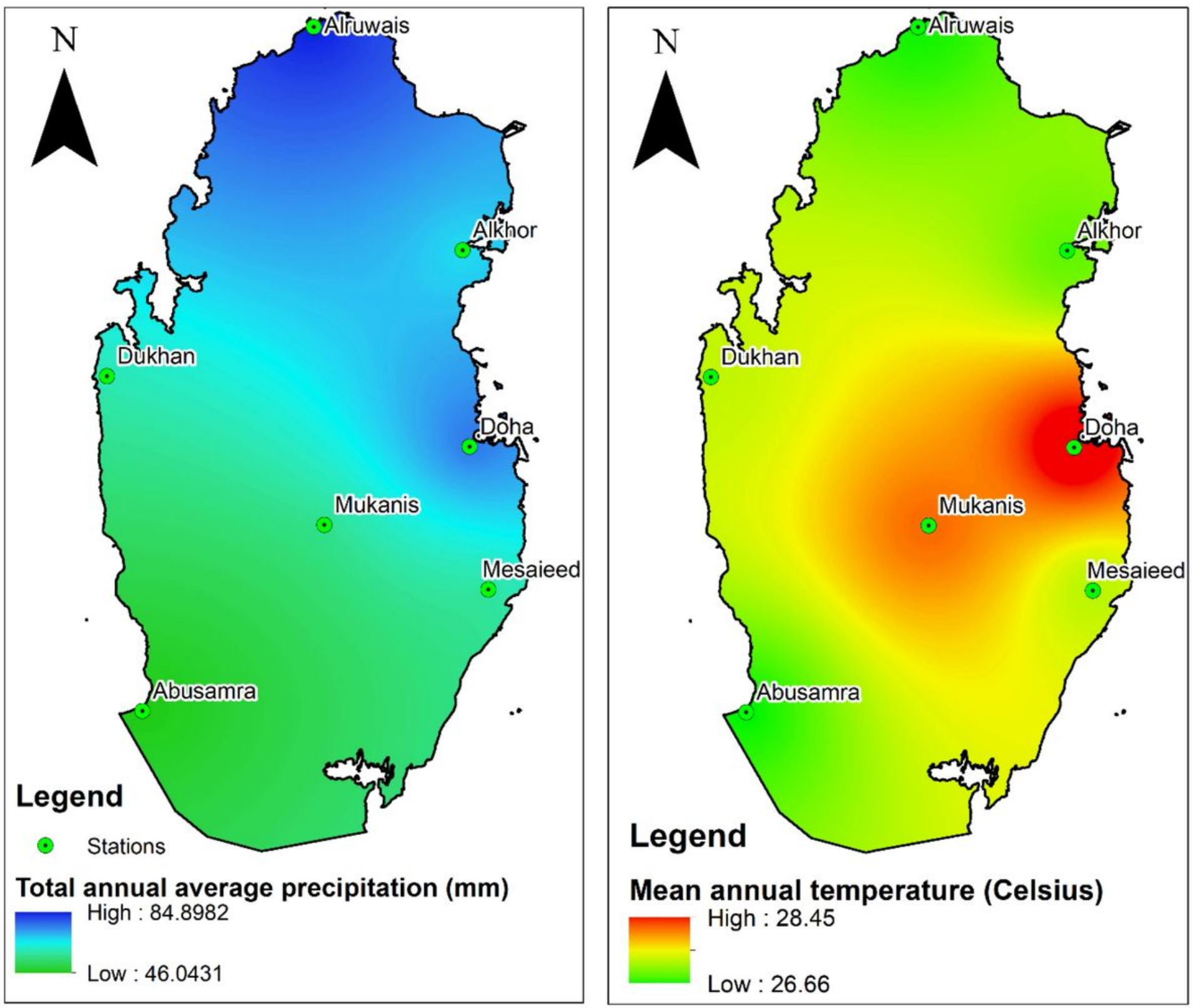

Figure 1

Digital Elevation Model DEM of the state of Qatar with weather stations location. 


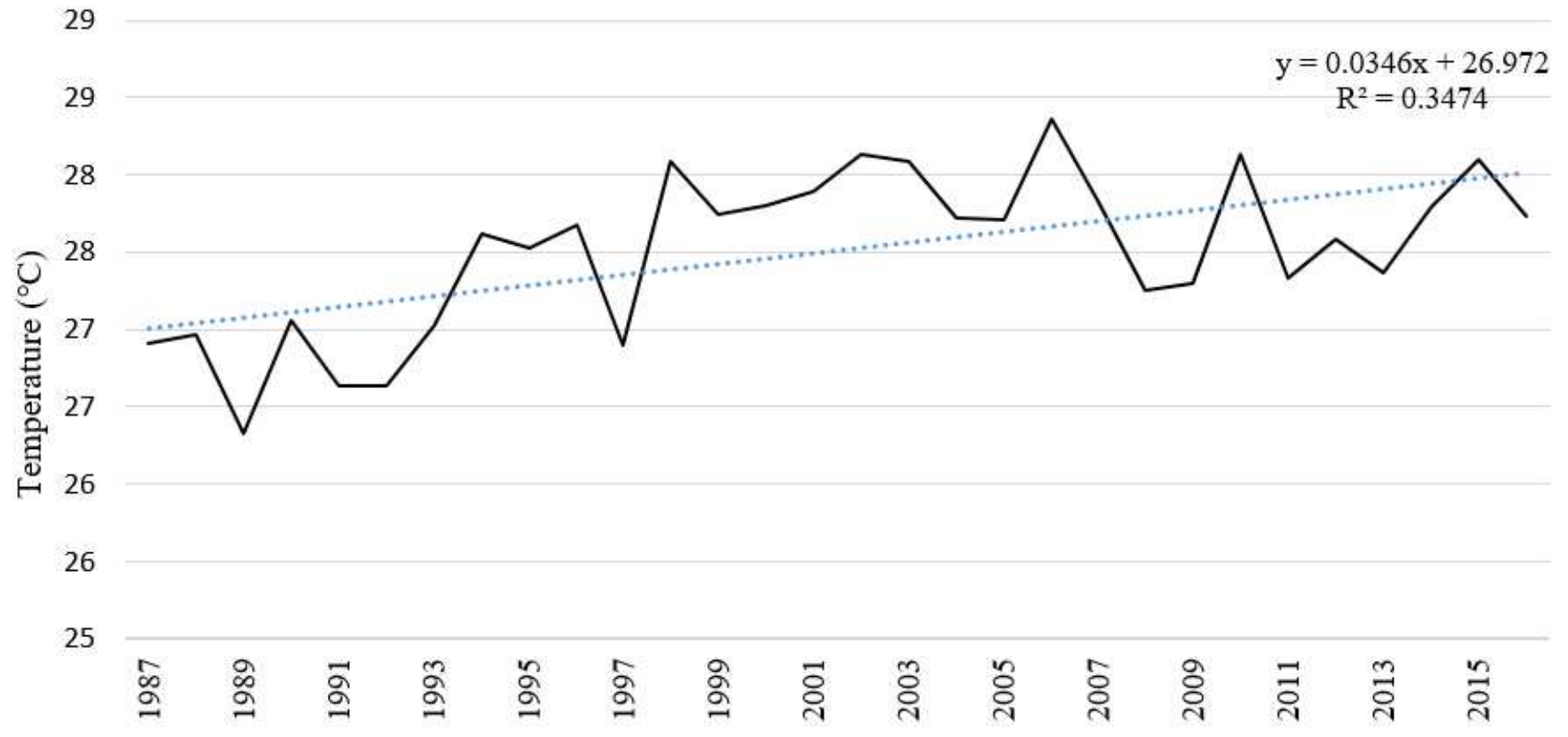

Figure 2

State-wide mean annual temperature in the state of Qatar from 1987-2016.

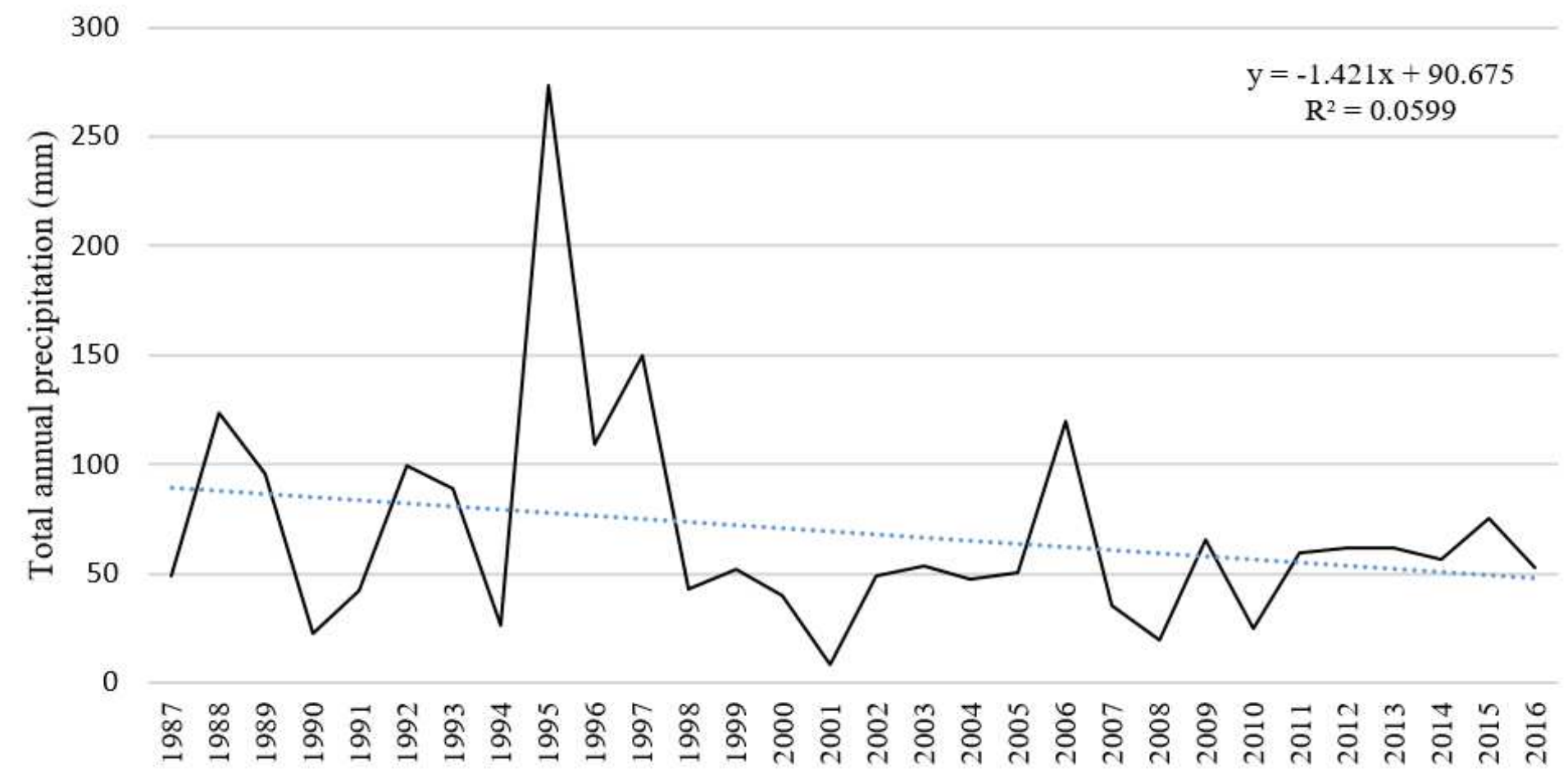

Figure 3

State-wide total annual precipitation in the state of Qatar from 1987-2016. 
DFJ

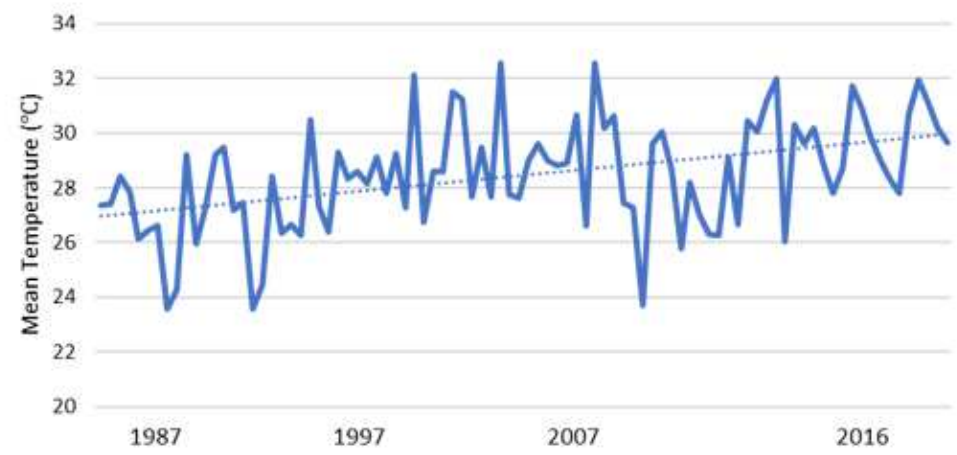

JJA

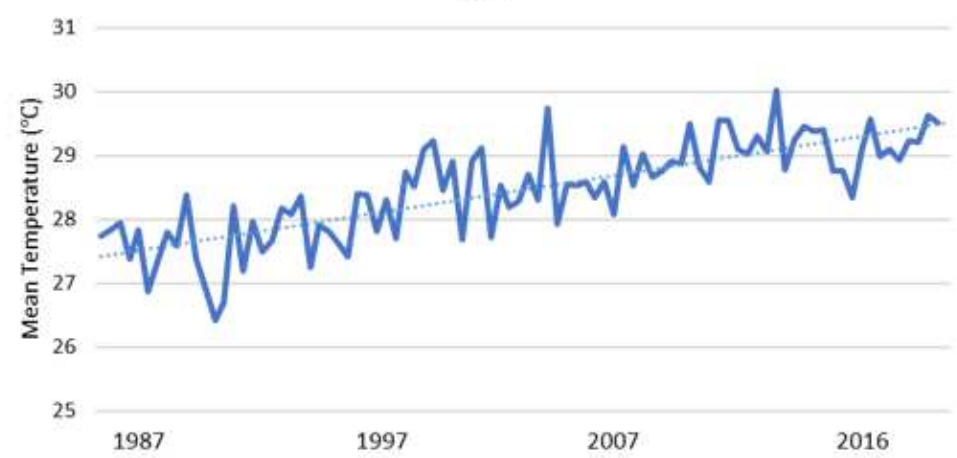

MAM
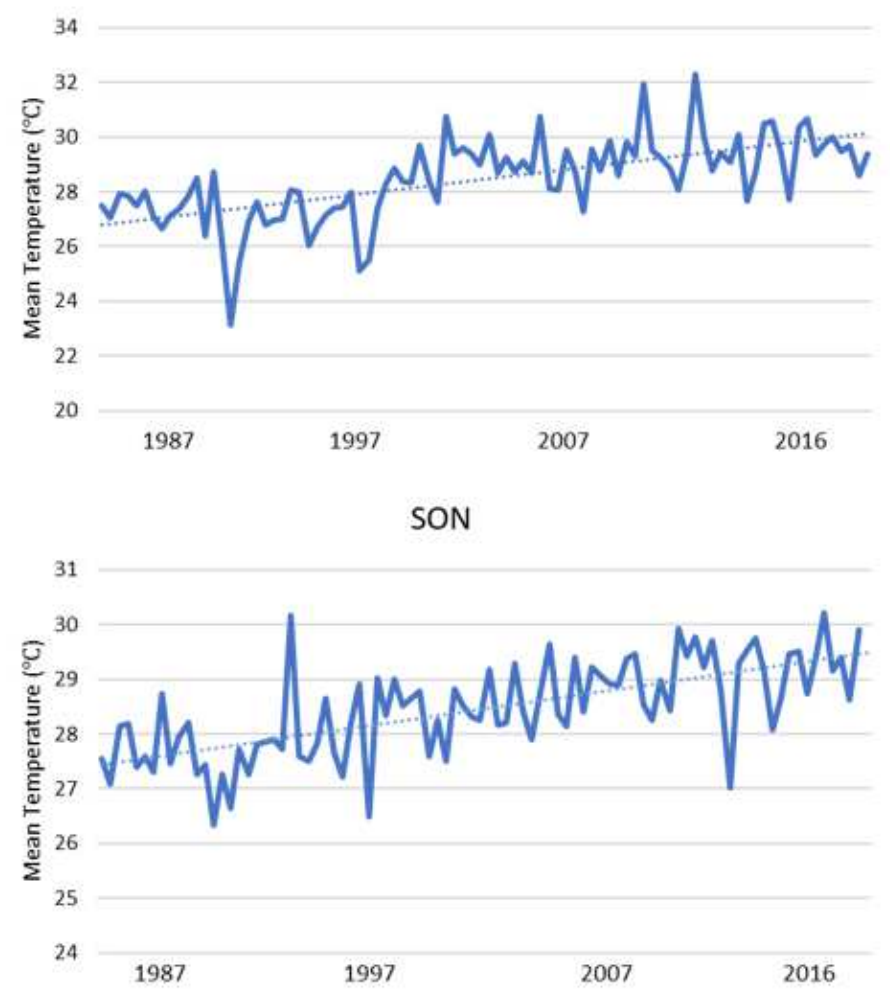

Figure 4

State-wide seasonal temperature trends 1987-2016.
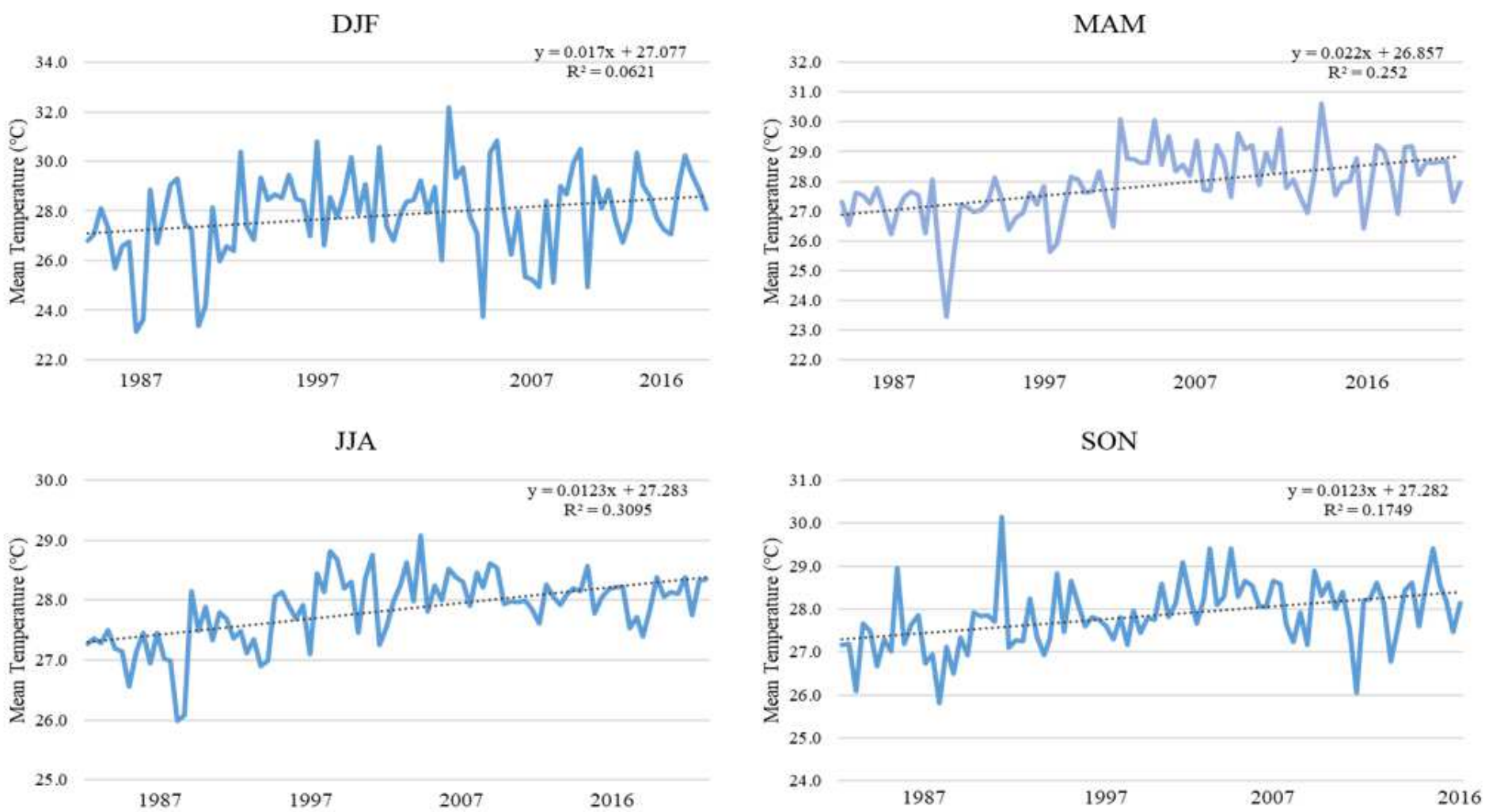

Figure 5 
State-wide seasonal precipitation trends 1987-2016.
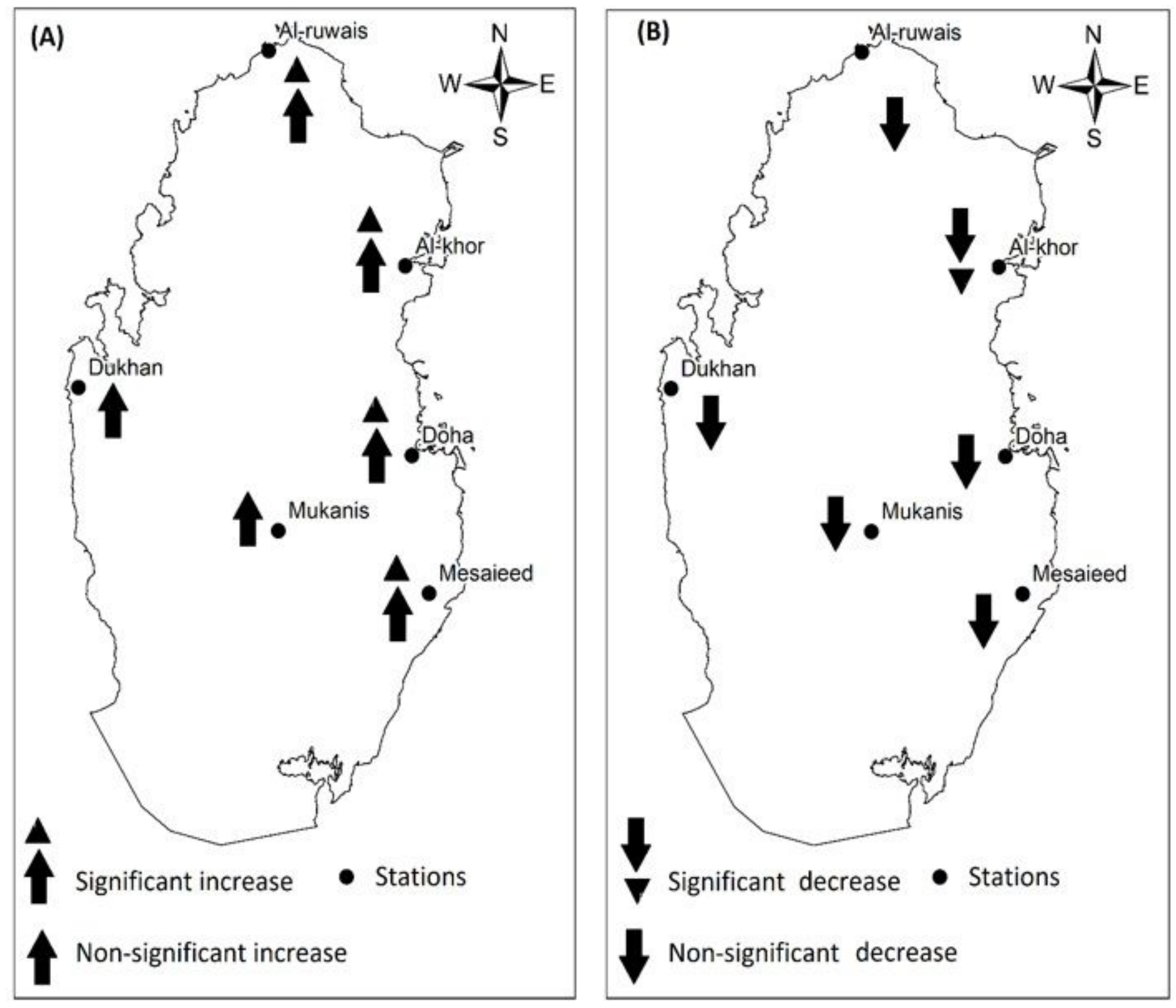

Figure 6

Station wise spatial variability in mean annual temperature (A) and total annual precipitation (B). 

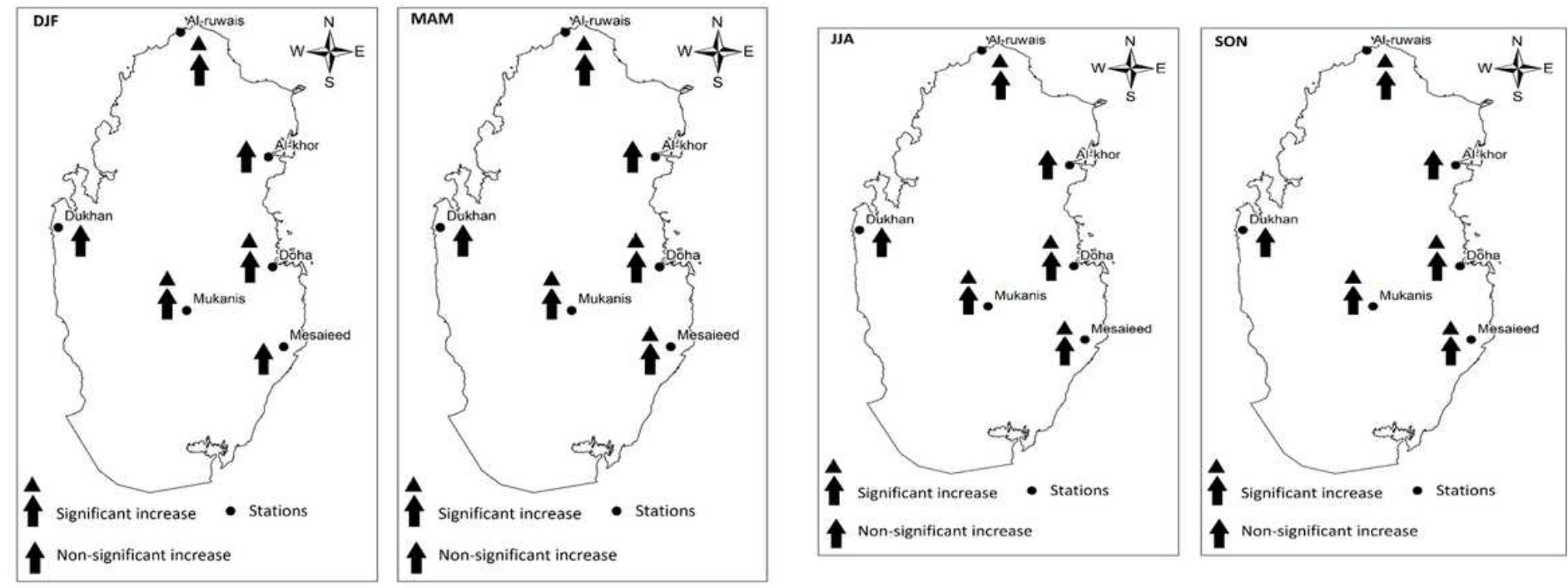

Figure 7

Station wise seasonal temperature trends.
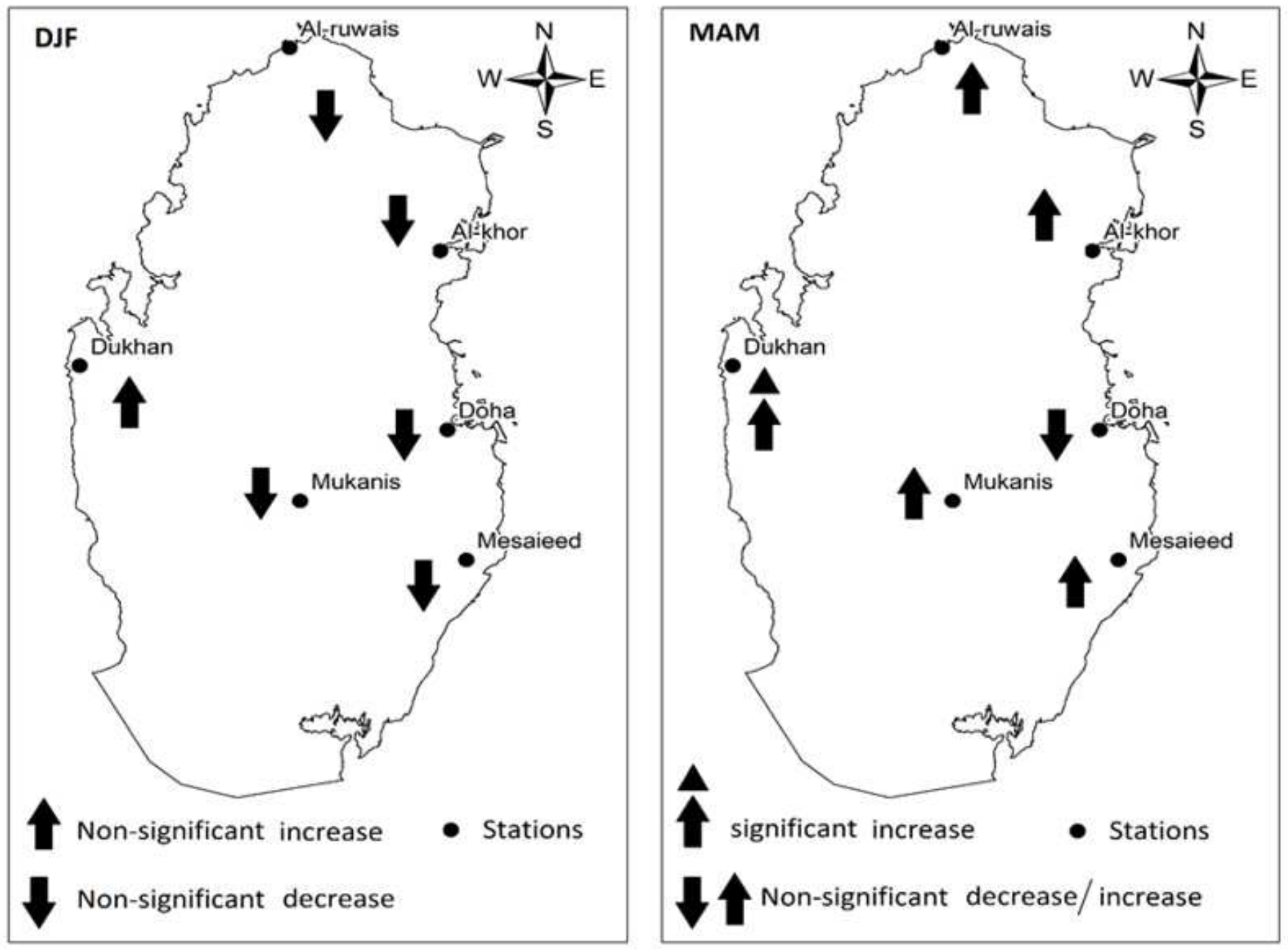

Figure 8 
Station wise seasonal precipitation trends.
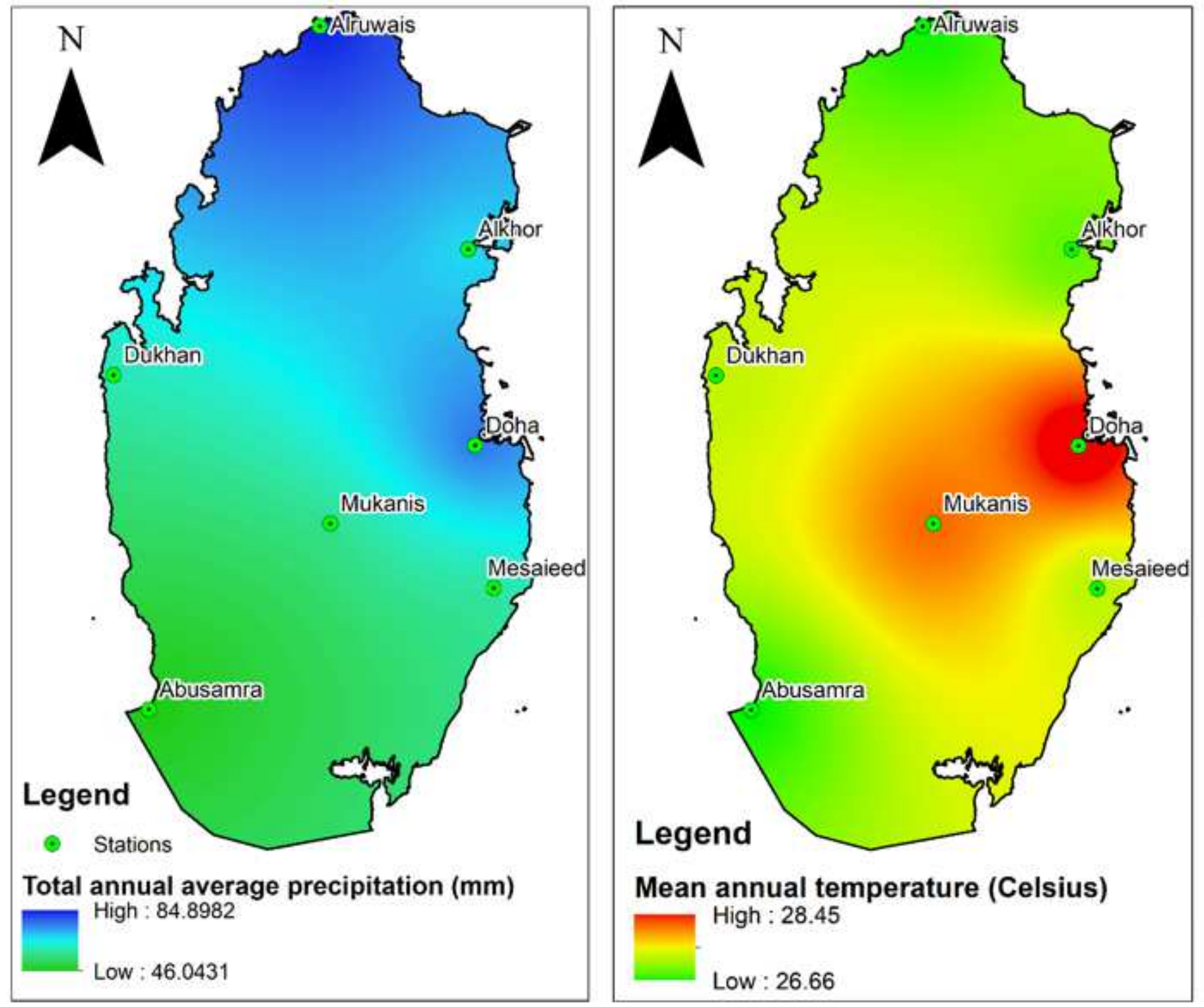

Figure 9

Spatial distribution of total annual precipitation and mean annual temperature over the state of Qatar. 


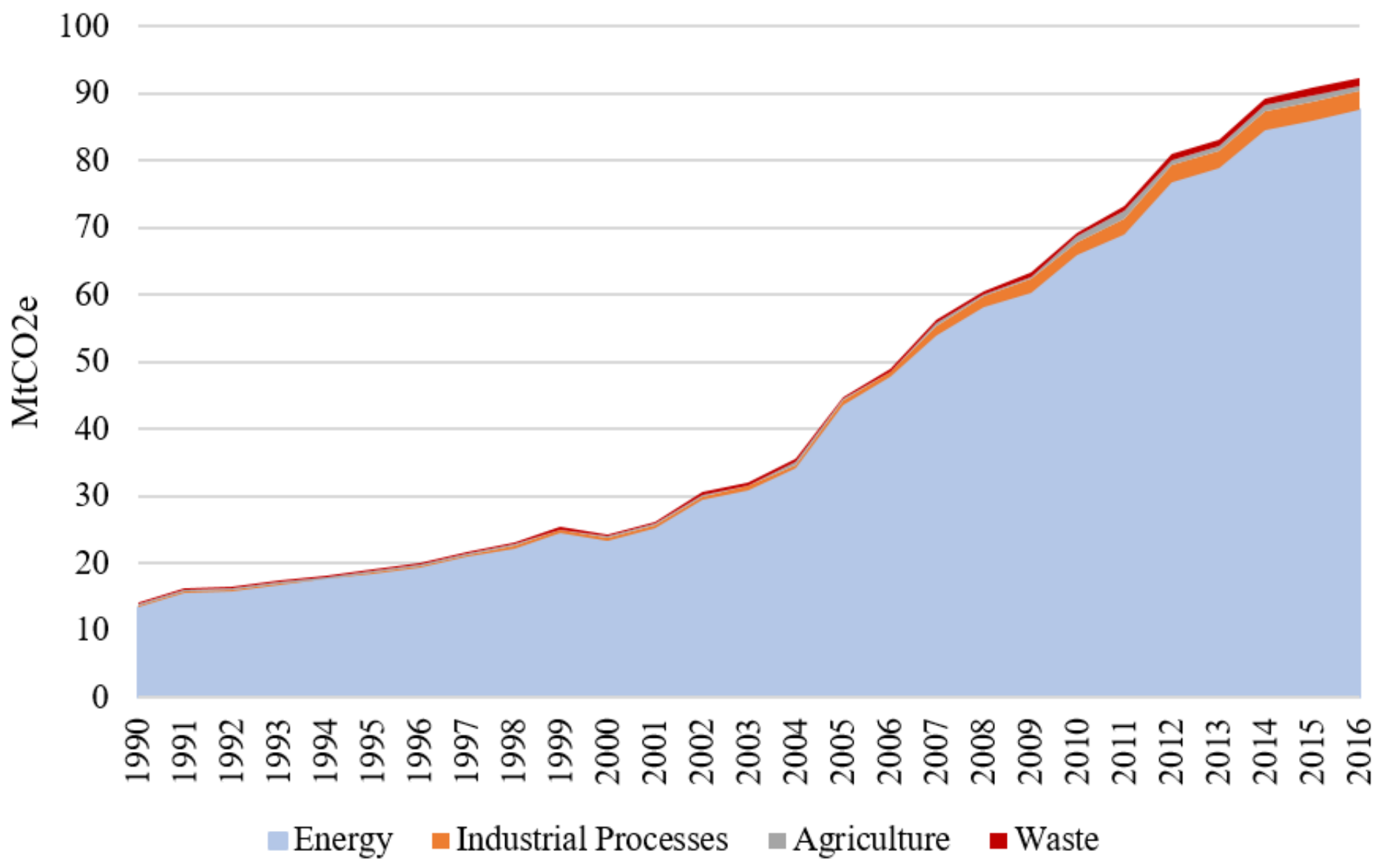

Figure 10

GHGs emission in the state of Qatar by sector from 1990 to 2016. Adapted from (WRI, 2016). 


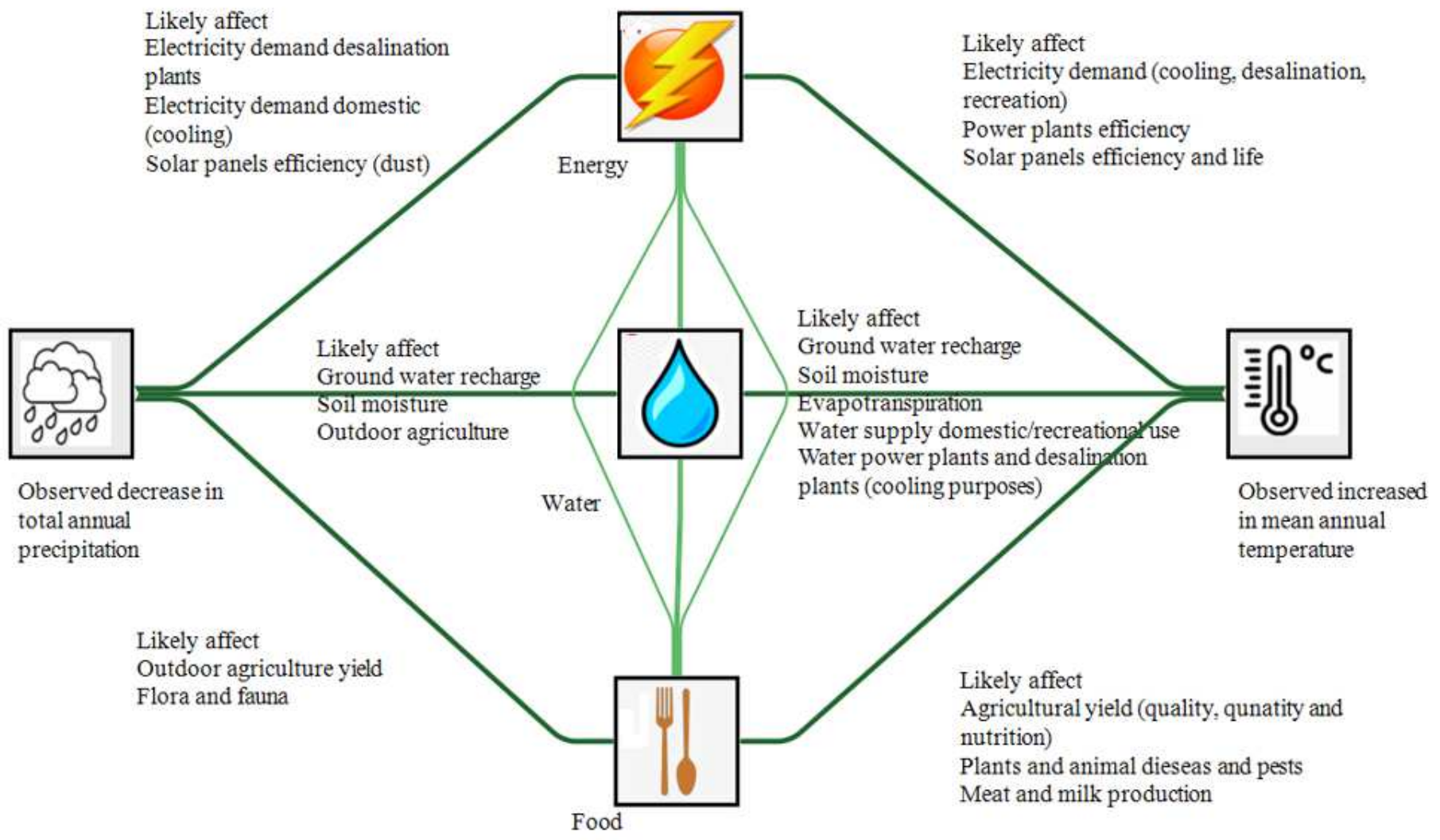

Figure 11

Possible impacts of observed climatic changes on the EWF nexus. 